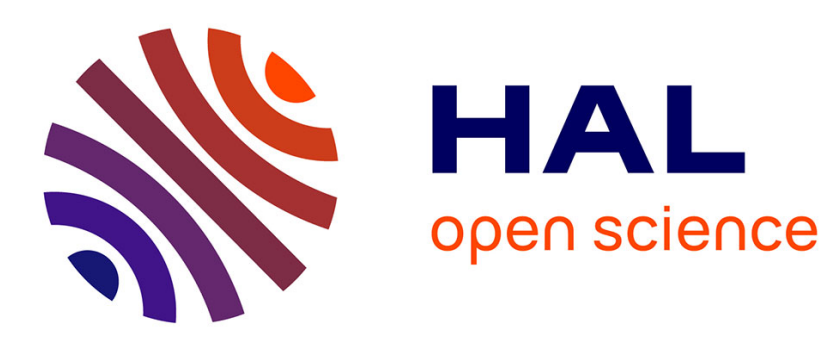

\title{
Climate impact analysis on the optimal sizing of a stand-alone hybrid building
}

Jules Voisin, Maxime Darnon, Abdelatif Jaouad, Maité Volatier, Vincent

Aimez, Joao Trovao

\section{To cite this version:}

Jules Voisin, Maxime Darnon, Abdelatif Jaouad, Maité Volatier, Vincent Aimez, et al.. Climate impact analysis on the optimal sizing of a stand-alone hybrid building. Energy and Buildings, 2020, 210, pp.109676. 10.1016/j.enbuild.2019.109676 . hal-02442654

\section{HAL Id: hal-02442654 \\ https://hal.science/hal-02442654}

Submitted on 1 Oct 2020

HAL is a multi-disciplinary open access archive for the deposit and dissemination of scientific research documents, whether they are published or not. The documents may come from teaching and research institutions in France or abroad, or from public or private research centers.
L'archive ouverte pluridisciplinaire HAL, est destinée au dépôt et à la diffusion de documents scientifiques de niveau recherche, publiés ou non, émanant des établissements d'enseignement et de recherche français ou étrangers, des laboratoires publics ou privés. 


\title{
Climate Impact Analysis on the Optimal Sizing of a Stand-Alone
}

\section{Hybrid Building}

\section{Jules Voisin ${ }^{1,2}$ Maxime Darnon ${ }^{1,2}$ Abdelatif Jaouad ${ }^{1,2}$ Maité Volatier ${ }^{1,2}$ Vincent Aimez ${ }^{1,2}$}

\author{
$\underline{\text { Joao } \text { Trovao }^{3}}$ \\ ${ }^{1}$ Laboratoire Nanotechnologies et Nanosystèmes, LN2, CNRS, Université de Sherbrooke, Qc, \\ Canada \\ 2 3IT (Institut Interdisciplinaire d'Innovation Technologique), Université de Sherbrooke, Qc, \\ Canada \\ ${ }^{3}$ Université de Sherbrooke, QC, Canada
}

Keywords: stand-alone building, sizing, genetic algorithm, solar power generation, climate

impact, renewable

Nomenclature

$\phi$ : latitude of the area $(-90 \leq \phi \leq 90)$

$\delta$ : Solar declination $\left(-23.45^{\circ} \leq \delta \leq 23.45^{\circ}\right)$

Wp : Peak Power (feature of a PV panel)

$\gamma$ : Surface azimuth angle $\left(-180^{\circ} \leq \gamma \leq 180^{\circ}\right.$;

PF : Penalty Function

$-90^{\circ}=$ due East)

$\beta$ : slope with respect to a horizontal plane.

EA : Evolutionary Algorithm

PSO : particle swarm optimisation

$\left(0^{\circ} \leq \beta \leq 180^{\circ}\right)$

$\omega$ : hourly solar angle

$\theta$ : solar incidence angle

ACA : Ant colony Algorithm

MILP : Mixed-Integer Linear Programming

LPSP : Loss of Power Supply Probability

$D C$ : Direct current

$\theta_{z}:$ solar zenith

$R_{b}:$ Geometric factor

SoC : State of Charge

GA : Genetic Algorithm

$\mathrm{H}_{2}$ : hydrogen

$\mathrm{H}_{2}$-tanks : hydrogen tanks

$\mathrm{H}_{2}$-SoC : state of charge of the $\mathrm{H}_{2}$-tanks.

MPPT : Maximum Power Point Tracker

$P$ : pressure $(\mathrm{Pa})$

$\mathrm{n}$ : amount of substance (mole)

$\mathrm{V}$ : volume $\left(\mathrm{m}^{3}\right)$

$\mathrm{T}$ : temperature $(\mathrm{K})$

$\mathrm{R}$ : gas constant $(8.314 \mathrm{~J} / \mathrm{K} / \mathrm{mol})$

AC : Alternative current

$p_{\text {battery }}$ and $p_{\text {tank }}$ : price respectively for batteries and $\mathrm{H}_{2}$-tanks (USD $\mathbf{W} / \mathrm{Wh}$ )

$p_{P V}, p_{\text {electrolyzer }}, p_{F C}$ : price respectively for the PV, electrolyzer and fuel cell (USD\$/W)

$N_{\text {batteries }}, N_{\text {tanks }}$ and $N_{P V}$ : number of batteries, tanks and PV arrays

$E_{\text {battery }}$ and $E_{\text {tank }}$ : rated energy that can be stored in a battery or a tank (Wh)

$P_{\text {electrolyzer }}$ and $P_{F C}$ : rated power of the electrolyzer and the fuel cell.

EMS : Energy management strategy

PV : Photovoltaic

$I_{r}$ : direct radiation $\left(\mathrm{J} / \mathrm{m}^{2}\right)$

$I_{d}:$ diffuse radiation $\left(\mathrm{J} / \mathrm{m}^{2}\right)$

$\rho_{s}$ : Reflection coefficient of the ground 
I : Global horizontal radiation on a $\eta_{\text {elec }}$ : loss in the PV system horizontal plane

$R_{b}=\frac{\cos (\theta)}{\cos \left(\theta_{z}\right)}:$ a geometric factor

$E_{k}$ : energy produced during the hour $\mathrm{k}$ of the day considered $(\mathrm{J})$

$S_{P V}:$ total area of the solar panels installed $\left(\mathrm{m}^{2}\right)$

$\eta_{\text {mppt }}$ : average efficiency of the installation

\section{Abstract}

In this paper, a new approach to study the impact of the climate on the optimal resultant sizing of a stand-alone PV/hydrogen/battery-based hybrid building is presented. A general method is described to evaluate the thermal need of the building, as well as the local photovoltaic resource, rather than using specific data available for large purpose applications. The proposed approach enables comparison studies between different places and climatic conditions. Considering a specific autonomous building, a comparative study is provided for different areas worldwide: Moscow, Cairo, Paris, Hanoi and Montreal. A Genetic Algorithm is used to provide an optimal size and energy capacity estimation for each location. The objective is to minimize the total cost while constraining the Loss of Power Supply Probability (LPSP) and the State of Charge (SoC) of the long-term storage element over one year. The sizing results between the different places demonstrate that the local climate has a huge impact on the final price, by highly modifying the PV resource and the thermal need of the building. The results demonstrate an $80 \%$ increase variation of the total installation cost between the area of Montreal and the one of Cairo. 


\section{Introduction}

In 2018 , more than $15 \%$ of the global population lives without any access to electricity, among whom more than $20 \%$ live in developing countries where a global electric grid is not available [1]. At the same time, the deployment of renewable energy sources is booming and still has a bright future in the following years: between 2010 and 2016, there have been almost two times more global average capacity additions of renewable systems than coal systems. Perspectives for the 20 following years show the same trend [2]. This leads to a significant decrease in price of renewable systems: for example, the installation price of a photovoltaic system decreased from around 12USD\$/Wp in 1998 to around 4USD\$/Wp in 2014 [3].

For buildings, they represent around $40 \%$ of primary energy needs worldwide and the current tendency is to develop structures using better materials and design that lead a real reduction in their energy needs [4]. This is shown in Canada, where "net zero" energy buildings require 4-times less energy than conventional buildings [5]. More and more projects are beginning to study the potential development of stand-alone facilities that use hybrid renewable energy sources like PV or wind turbine to answer the energy needs of the building [6].

The main difficulty in developing an energy-independent building is the sizing of its energetic components, because the system should work throughout the year, even if the current consumption is greater than expected or the PV production is too low. Up to now, the impact of the local climate has never been considered in the way it modifies the load of the building throughout the year, even if it is of paramount importance. An optimal sizing is necessary for security and reliability of the system [7]. 
Many different algorithms have been developed and are well-known nowadays. For example, Yang, Lu, Zhou and Fang proposed an optimal sizing of a stand-alone hybrid solar-wind system using a Genetic Algorithm (GA) that evaluates the Loss of Power Supply Probability to make a proper sizing of the facility under study [8]. They use weather data (daily radiation, average wind speed and ambient temperature) to estimate the PV production and wind production of the system. A year of hourly-based data of an arbitrary load is also used to feed the simulation, without giving any other details on their model, in order to be replicable.

In [9], a sizing using a multi-objective design is proposed for a stand-alone house. The authors have developed an Elitist GA applied to a Multi-Objective design of a hybrid PV-wind-battery system, using a real load profile. However, this real electric consumption data excluded uses for cooking, heating and hot water production. In other words, the overall thermal need of the house is not properly represented, leading to uncertainties in the sizing due to seasonal variation. In [10], the authors themselves mentioned the fact that the impact of the thermal demand on the sizing should be investigated more deeply, even though they proposed a very efficient multi-objective algorithm for sizing.

Only few articles studied the long-term energy storage, on a multi-week timeframe. This is directly explained by the fact that the climate is never considered in the way it modifies the load of the building. Thus, the articles only focus on the PV or wind input of energy, varying with the seasons. However, this impact is not very important if the variation of the load of the building through heating is not considered. A stand-alone facility may lead to a decrease of robustness for the whole facility if the solar input does not match the estimated consumption. In [11], the authors propose a sizing of such a hybrid system, using hydrogen as a long-term storage system. The authors also propose different energy management strategies for sizing 
the system to define the size of the electrical devices and the energy capacity of the batteries and $H_{2}$-tanks, using an annual solar input, which included the seasonal variation. However, they simply propose an average daily load profile that does not include the seasonal variation of the thermal need of the building.

In [12], the authors have a closer look at the electrical load profiles of the building, showing the breakdown between each element (lighting, heating appliances, audio-visual and so on). They also make a distinction between a typical summer day and a typical winter day. However, there is no thermal study of the house, which makes it quite difficult to study the seasonal impact of the thermal consumption.

Many related works focus on a way to get an optimal sizing method, resulting in a methodology that only tries to make the sizing of a specific facility, place and configuration. More precisely, they use known electric load data and keep constant the weather under study, but do not focus on the link that exists between the climatic condition and the total load data of the building, as well as, the PV resource [13].So far, the local climate impact on the sizing of the facility has not been analysed between different locations, whereas thermal models of buildings already exist and are well documented[14].

In this paper, a new approach is proposed. An optimal sizing of the stand-alone building using models to estimate the PV resource and thermal needs is proposed. The building is supposed known with fixed key features and the local climate is considered in the sizing using local meteorological data (sunshine, temperature) to estimate the thermal need and the PV production. Thus, the approach allows the comparison of various locations with different weather conditions, in order to highlight the impact of the climate on the sizing of stand-alone buildings. Thanks to this general approach, the paramount importance of the local climate on 
the sizing of the building can be highlighted, between different locations worldwide. This makes it possible to understand what the key parameters are to be considered when dealing with stand-alone buildings. This method also allows an estimation without any previous knowledge of PV production or the total building load. The strengths of this method are based on the thermal demand (as well as the PV resource) that is estimated from scratch using very general information about the building and is not the result of any specific consumption data. A thermal model of the building along with an accurate solar resource estimation is used in order to evaluate the annual global thermal building requirement and annual solar production capacity. The solar resource is thereby estimated using the best model known in the literature. However, this remains an estimation using a typical meteorological year or equivalent, on an hourly basis, obtained using several years of data [15]. A three-node thermal model of the building is used to estimate the thermal capacity quickly and accurately [16]. An electric consumption profile is simultaneously considered [14], to reach a general purpose model suitable to any place or climate conditions. Thanks to this general approach, a comparison study is available and realized for 5 different locations worldwide. For each location and by fixing the general features of a selected building, the maximum PV resource is estimated, and the load profile is determined. Thereafter, a sizing is realized using a GA that aims to minimize the cost while constraining the Loss of Power Supply Probability (LPSP) and the final State of Charge (SoC) of the hydrogen storage elements $\left(\mathrm{H}_{2}-\mathrm{SoC}\right)$. The robustness of the optimal sizing is validated for each location by repeating 10 times the sizing with the exact same inputs and by analysing the penalty function and the constraint through each generation. Finally, a comparative analysis based on total cost is presented between the various locations. 
This paper is organized as follows: Section 2 describes the configuration of the hybrid system under study, the proposed sizing method, the input and output needed for the sizing and the simple used energy management strategy. The modelling of the whole hybrid system is described, including the PV contributions and the electrical and thermal need of the facility under study. The simulation results are presented and discussed for one case study in section 3 and a comparison sizing is done and discussed between several places with different climates. This section also addresses the robustness analysis and the results are presented for 2 locations. Finally, Section 5 addresses conclusions and future steps. 


\section{Modelling and optimal sizing strategy}

\subsection{Hybrid system configuration}

The full configuration of the energy independent hybrid system under study is presented in Figure 1. The hybrid system is composed of one PV array (which constitutes the only input of external energy), a battery pack and a hydrogen system. The hydrogen system is composed of an electrolyzer that converts the PV electricity into hydrogen that is then compressed into $\mathrm{H}_{2}$ tanks for long-term storage. The hydrogen energy is given back to the DC grid through a fuel cell then connected to the DC bus through a DC-DC converter.

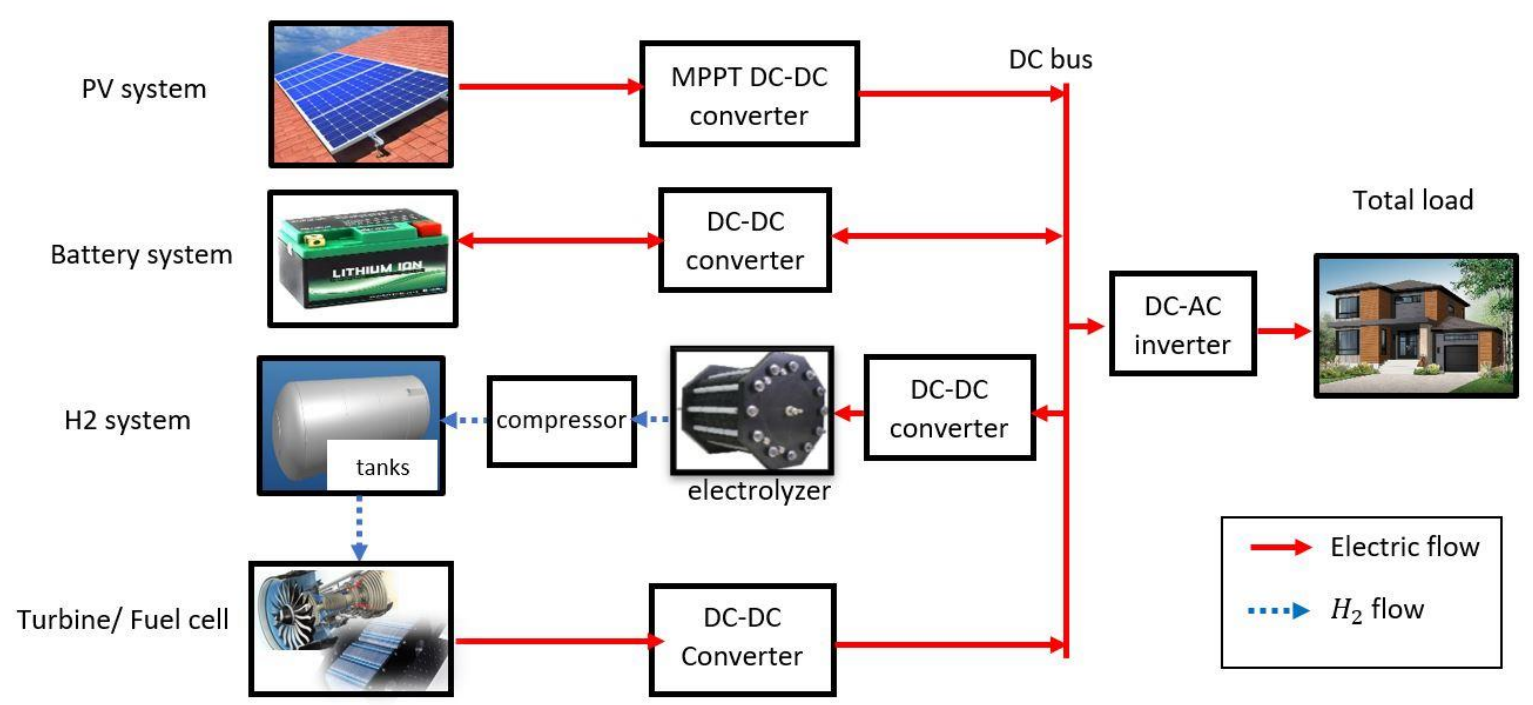

Figure 1: Schematic diagram of the stand-alone hybrid system

As the main objective of this work is the optimal sizing of an independent building's energy resources, the simulation should be fast and a sample resolution of 1 hour is selected. The very short-term power flow analysis is not considered and storage systems with fast dynamics (supercapacitors or flywheels) are not under evaluation here. However, these types of storage 
systems should be considered in the final stage design, to refine the energy management, help the battery pack and the electrolyzer with fast dynamic power variations and increase their lifetimes [17].

The input of energy is totally done by the PV array. The battery carries out the absorption and restitution of energy on the scale of a day and it is preferred to the $\mathrm{H}_{2}$-system due to its better global efficiency. Storing a huge amount of energy in batteries is highly expensive, but efficient from an energy point of view. On the other hand, storing energy in the form of pressurized $\mathrm{H}_{2}$ is cheap, but the whole efficiency is low. A trade-off must be made and a long-term storage in the form of pressurized $\mathrm{H}_{2}$ must be considered as it allows to reduce the total price of the system.

The procedure used to size the energy independent house is as follows: first, the annual PV input of energy for the studied location is evaluated, as well as the annual thermal and electrical need of the house. Sizing the system is done by determining the number of PV cells, the number of batteries, the number of $\mathrm{H}_{2}$-tanks and the rated power of the electrolyzer and its respective fuel cell. These five parameters should be selected in order to minimize the price while constraining the LPSP and $\mathrm{H}_{2}$-SoC. The penalty function (PF) calculates the total investment cost, while the constraint function demonstrates an annual simulation of the system and returns the LPSP and $\mathrm{H}_{2}$-SoC at the end of the year. That means the best configuration should be computed under five decision variables, leading to the use of a specific algorithm to quickly find the optimal solution. An optimization algorithm evaluates the defined penalty and constraint functions under a given configuration to return the optimal solution. As a stop condition for the algorithm, the system should operate under normal conditions at least $95 \%$ of the time (LPSP $\leq 0.05)$ under the lowest investment cost, with an 
$\mathrm{H}_{2}$-SoC at the end of the year that is equal or superior to the one at the beginning, including a $5 \%$ margin.

\subsection{Optimal Sizing Approach}

To size the independent building, an hourly-based simulation of the whole system throughout the year is done considering a realistic Energy Management Strategy (EMS). The EMS proposed here is based on control states and is fully depicted in Figure 2.

Ipsakis, Voutetakis, Seferlis, Stergiopoulos and Elmasides present a parametric study of different EMS for the power management of a stand-alone system [18]. The results show that one of the presented EMS resulted in lower operation time and higher hydrogen inventory compared to the other EMS systems also tested. The EMS presented in this study is an evolved version of the best EMS presented in [19], considering the following improvements: the maximum power flowing through the batteries, the $\mathrm{H}_{2}$-SoC of the $\mathrm{H}_{2}$-tanks and a thermal recovery are considered, that results in the decision flowchart presented in Figure 2. Even if this EMS may not be optimal, the optimal building will be reached considering such an EMS. 


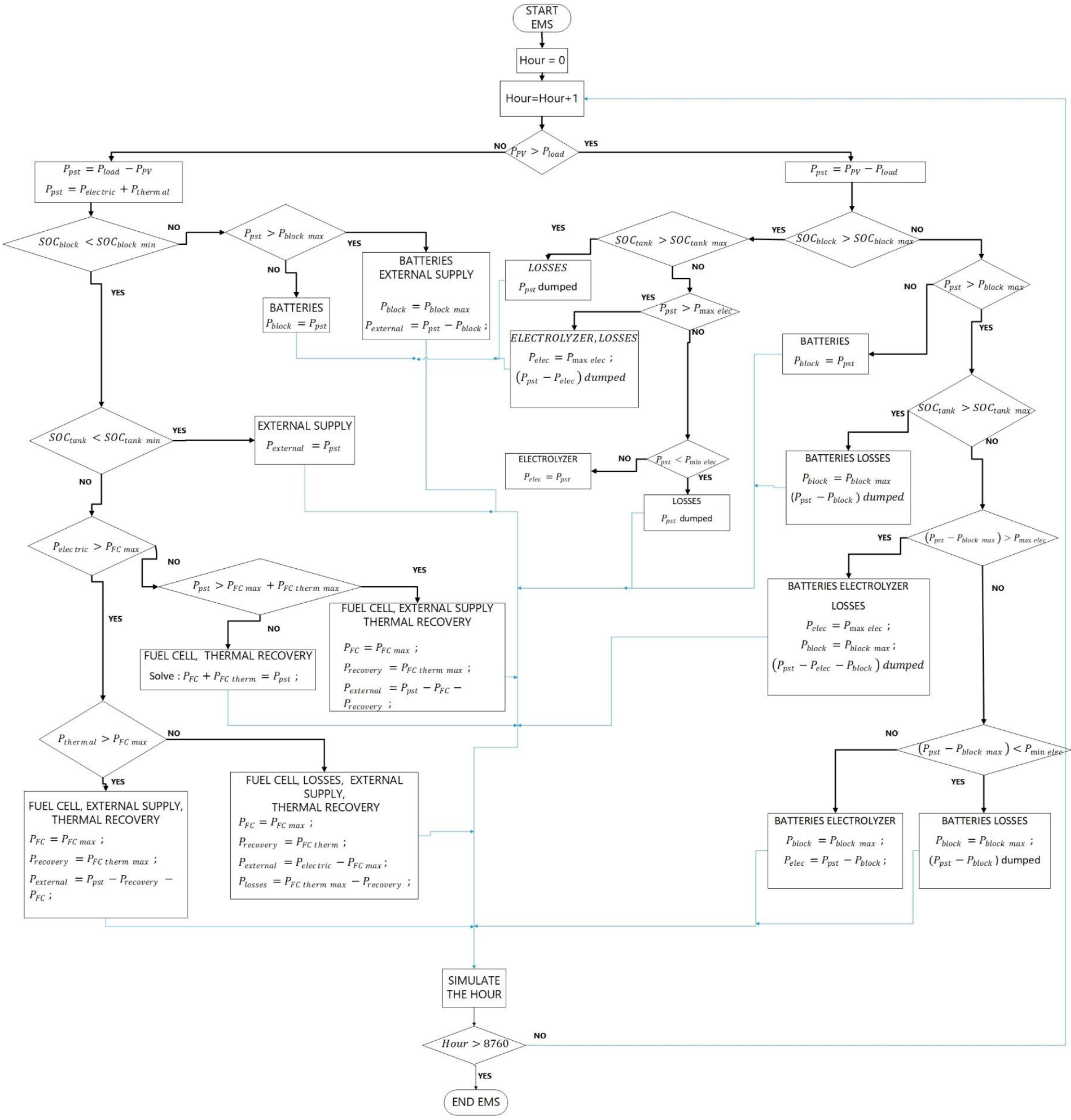

Figure 2: logical block of control states for EMS

This logical block operates by steps: first, it is determined if we are in excess or in deficit of power, by computing the difference between $P_{P V}$ and $P_{\text {load }}$, respectively the power coming 
from the PV panels and the one from the load of the building. If we are in excess, it means we can store this available power $P_{p s t}(>0)$ in the batteries and/or $\mathrm{H}_{2}$-tanks. The block of batteries is considered first because of their better efficiency and the block is reloaded if its state of charge $S o C_{b l o c k}$ is not full. At each step, it is checked that we do not overload the available power of the batteries $P_{\text {block } \max }$ and/or the one of the electrolyzer $P_{\max \text { elec }}$. We also check that the power is high enough $\left(P_{\min \text { elec }}\right)$ to be able to activate the electrolyzer. The remaining power available after redirecting the flow between the batteries and the electrolyzer is considered lost. If we are in deficit of energy, it means we need to discharge the batteries and/or the $\mathrm{H}_{2}$-tanks. We have thus a power $P_{p s t}(>0)$ to deliver to the building. We calculate the fraction of this load that is electric $P_{\text {electric }}$ and the one that is purely thermal $P_{\text {thermal }}$. The general idea is then to use the important thermal losses of the fuel cell $P_{F C}$ therm to directly warm up the building. Once more, batteries are considered first for efficiency reason.

This EMS has to be coupled with an optimization strategy to catch its full benefit resulting in an optimal sizing of the system. To optimize the sizing of the system, 5 integer variables are defined: the number of batteries $N_{\text {batteries, }}$, the number of PV arrays $N_{P V}$, the rated power of the electrolyzer $P_{\text {electrolyzer }}$, the number of $H_{2}$-tanks $N_{\text {tanks }}$ and the rated power of the fuel cell $P_{F C}$. Thus, the optimal sizing is obtained after finding the best combination of 5 integers variables where the penalty function is linear, and the inequality constraints are non-linear (variables defined below). There are several strategies available for optimization purposes and some works have already been done to highlight that the use of evolutionary algorithms (EAs) is a very good approach for global and direct searches in our case [20]. Among them, simulated annealing, particle swarm optimisation (PSO), ant colony algorithm (ACA), taboo search or 
genetic algorithm (GA) are the most commonly used. Evolutionary algorithms (EAs) are stochastic search methods that mimic the social behaviour of species and/or the natural biological evolution to find a near-optimum solution for complex and large-scale optimisation problems. EAs like PSO, ACA or GA have been analysed and compared in the literature, resulting in similar performance [21]. Moreover, the sizing here deals with integer values that represent the number of batteries, tanks and PV arrays. We also consider fixed step of rated power for the fuel cell and electrolyzer, as manufacturers can't provide them for a very specific value. We have thus to deal with Mixed-Integer Linear Programming (MILP) while making the optimization. This kind of optimization is already known in designing building supply systems [22]. For instance, Lozano, Ramos and Serra proposed a cost optimization of the design of a building system using a MILP [23]. The Matlab's global optimization toolbox already proposes a function that enables to use a genetic algorithm to solve this kind of Mixed Integer Optimization problem. As this paper proposes to use an EA as a tool rather than compare different EAs each other, this function was thus selected in this study.

Thus, the EMS presented is coupled with a GA to properly size the stand-alone system. GA is nowadays used in a wide range of areas. GA is inspired by natural biological process' improved fitness through evolution. At each generation, a set of possible solutions is returned, each solution is considered as an individual composed of set of elements called 'genes' that hold a set of values for the optimization variables. GA works with a random population of individuals, where each individual is evaluated through a penalty function (PF). The best individuals, if they equal or improve the solutions, are then used and mixed together (through mutation and crossover) to pave the way for the new generation of the population. 
The PF (1) calculates the cost of the entire facility, given the number of batteries, PV arrays, the rated power of the electrolyzer and the fuel cell and finally the volume of $\mathrm{H}_{2}$-tank.

$$
\begin{gathered}
p_{\text {total }}=p_{\text {battery }} N_{\text {batteries }} E_{\text {battery }}+p_{P V} N_{P V} W p_{P V}+p_{\text {electrolyzer }} P_{\text {electrolyzer }} \\
+p_{F C} P_{F C}+p_{\text {tank }} N_{\text {tanks }} E_{\text {tank }}
\end{gathered}
$$

with:

- $\quad p_{\text {battery }}$ and $p_{\text {tank }}$ the price respectively for batteries and $H_{2}$-tanks (USD\$/Wh).

- $p_{P V}, p_{\text {electrolyzer }}, p_{F C}$ the price respectively for the PV, electrolyzer and fuel cell(USD\$/W)

- $\quad N_{\text {batteries }}, N_{\text {tanks }}$ and $N_{P V}$ number of batteries, tanks and PV arrays.

- $E_{\text {battery }}$ and $E_{\text {tank }}$, rated energy that can be stored in a battery or a tank.

- $W p_{P V}$ peak power of the selected array.

- $\quad P_{\text {electrolyzer }}$ and $P_{F C}$ rated power of the electrolyzer and the fuel cell.

Only the more relevant values in the cost penalty function are used and only one type of batteries for the whole system is considered. For the battery system, with the system described here (i.e. batteries put in parallel, to fix the network voltage), it is equivalent to consider the total energy or the maximum power of the batteries in the cost function:

$$
\begin{aligned}
& P_{\text {block } \max }=\frac{E b a t^{2}}{4 * R_{\text {block }}}=N_{\text {batteries }} * \frac{E b a t^{2}}{4 * \text { Rbat }}=N_{\text {batteries }} * P_{\text {bat max }} \\
& \text { Energ } y_{\text {block }}=N_{\text {batteries }} * \text { Energ }_{\text {bat }}
\end{aligned}
$$

Thus, considering an "energy" cost plus a "power" cost for a battery:

$$
\begin{gathered}
p_{\text {total_batteries }}=p_{\text {energy }} N_{\text {batteries }} E_{\text {battery }}+p_{\text {power }} * N_{\text {batteries }} * P_{\text {bat max }} \\
p_{\text {total_batteries }}=N_{\text {batteries }} *\left[p_{\text {energy }} E_{\text {battery }}+p_{\text {power }} P_{\text {bat max }}\right]
\end{gathered}
$$

We have considered the use of batteries of type "energy". We could have taken batteries of type "power" but the purpose is to optimize the whole building and not the batteries 
themselves. One improvement could be to mix "energy" batteries and "power" batteries in the system and distinguish $N_{\text {batteries "power" }}$ from $N_{\text {batteries "energy" }}$

For the GA, we set two constraints on the candidate solutions: the LPSP should remain below a threshold of 0.05 and the $\mathrm{H}_{2}-\mathrm{SoC}$ at the end of the year should be no less than the amount found at the beginning of the year (sustainability condition). A threshold of $5 \%$ is set for the LPSP and the initial $\mathrm{H}_{2}$-SoC is set equal to $50 \%$.

The proposed PF (1) is linear but the two constraints are not linear and we do have 5 parameters to optimize in a very extensive domain. In these situations, classical algorithms that generate a single point for each iteration and select the next point with deterministic computation are not appropriate. On the contrary, the GA which generates a population of several individuals at each step, is much more appropriate and ensures the best solution. For this reason, the GA was chosen for this application.

To evaluate the two constraints (LPSP and $\mathrm{H}_{2}$-SoC), an hourly simulation of whole system is completed. At the end of the year time scope, the LPSP and $\mathrm{H}_{2}$-SoC are evaluated. Thereafter, the GA is used to compute the optimal solution. The GA parameters are: a population size of 300 individuals, a maximum of 200 generations and a stall of the genes after 125 generations. At each generation, we keep the 15 best individuals, set as elite (5\%). Among the 95\% remaining parents, we have a crossover fraction of 50\%, meaning that 143 children are crossover children and 142 are mutation children. We use a basic crossover function: the child vector has each of its gene coming randomly from one of the two parents. The mutation children are created by randomly changing each of the parents' gene, following a gaussian distribution. To accelerate the simulation, parallel computing is used to utilize the 4 cores of 
the computer (Intel Core i7-7700HQ CPU @ 2.80GHz, 4 cores, 8 logical processors), resulting in a simulation that takes less than 5 minutes to compute.

It is critical that the simulation which evaluates the two constraints accurately represents the variation of the $\mathrm{H}_{2}$-SoC and the battery SoC over the year. Indeed, it is only under this condition that we can ensure the whole system is properly sized and will operate well for at least $95 \%$ of the time. This means that a time scope of one year must be used. Some authors only consider a time scope of several weeks up to several months [19]. Moreover, the seasonal variation of the climate is almost never taken into account in the global load of the building [24]. However, the seasonal variation of the climate should not be neglected, since the PV energy production and also the energy needed to heat the building over one-year are linked to the different seasons. The proposed model uses a full year of climate data to estimate the thermal need and PV production, which is the most accurate estimation since these needs and productions vary based on the climate throughout the year. Under this condition, the oneyear simulation can provide reliable results on the performance of the independent building, by supplying accurate initial estimations of the LPSP and $\mathrm{H}_{2}$-SoC. Note that the optimal sizing obtained is optimal in the framework of the chosen EMS, and costs of components. If one chose another EMS or other costs of components, other optimal sizing may be reached. 


\subsection{Modelling of the hybrid system}

\subsubsection{Modelling electricity production from solar energy}

For the hybrid system under study, the electric energy provided by the solar resource must be estimated. This must be a function of the PV arrays, the geographical position and the mechanical position of the arrays. The PV arrays performance is highly influenced by the local radiation and their orientation. Many studies propose a way to estimate the solar production [25]. The whole methodology used actually to estimate the power production is based on a method designed by Clark et al. and tested by Menicucci [26]. This latter has made a robustness analysis that has demonstrated that this method produces reliable results, with differences between 1 and $4 \%$ with a real system if we consider measured radiations directly on the system. The equations used are mainly extracted from [26], based on the most commonly used method of estimating energy solar production. Meteorological data for the considered location is gathered freely on the EnergyPlus website [27]. The position of the sun is obtained using the Duffie and Beckman's equation [28]. Different radiation calculations can be made, using different sky models. Among them, the HDKR model, the Perez Model and the Isotropic Sky Model are the most well-known. We consider an optimal orientation of the panels in this study. Thus, the isotropic sky model is used, as the panels mainly face the sun to maximize the photovoltaic production. This model is used to estimate the total solar radiation on a tilted surface by (4).

$$
I_{T}=I_{r} R_{b}+I_{d}\left(\frac{1+\cos (\beta)}{2}\right)+I \rho_{s}\left(\frac{1-\cos (\beta)}{2}\right)
$$

with:

- $I_{r}$ : direct radiation $\left(\mathrm{J} / \mathrm{m}^{2}\right)$, obtained through the weather data

- $I_{d}$ : diffuse radiation $\left(\mathrm{J} / \mathrm{m}^{2}\right)$ (weather data) 
- $\rho_{s}$ : Reflection coefficient of the ground $\left(0 \leq \rho_{s} \leq 1\right)$

- $I$ : Global horizontal radiation on a horizontal plane (weather data)

- $R_{b}=\frac{\cos (\theta)}{\cos \left(\theta_{z}\right)}$ : a geometric factor

- $\beta$ : slope with respect to a horizontal plane. $\left(0^{\circ} \leq \beta \leq 180^{\circ}\right)$

Once the total solar radiation is calculated for a specific hour of a specific day of the year, the solar production for that hour can be evaluated using (5):

$$
E_{k}=S_{P V} I_{T} \eta_{m p p t} \eta_{\text {elec }}
$$

with:

- $E_{k}$ : energy produced during the hour $\mathrm{k}$ of the day considered (J)

- $S_{P V}$ : total area of the solar panels installed $\left(\mathrm{m}^{2}\right)$

- $\eta_{m p p t}$ : average efficiency of the whole installation equipped with a Maximum Power Point Tracker (MPPT) algorithm.

- $\eta_{\text {elec }}$ : loss mainly due to dust, the joule effect and standard deviation.

Finally, the efficiencies $\eta_{m p p t}$ and $\eta_{\text {elec }}$ are estimated using equations mainly presented in [26], while the characteristics of the arrays are extracted from a solar panel directory [29].

We do not superpose an uncertainty model to that model, as it is considered already included in the used approach (sky model plus the weather data). On the top of that, some parameters will be of paramount importance in practice and cannot be relevant in such a study, like the shadow induced by the surrounding environment.

\subsubsection{Modelling of the thermal needs of the considered house}

A method of determining a thermal need profile of the house throughout the year is presented below. To do so, the house is initially assumed to be a two-node system, as shown in Figure 3. Indeed, we consider the building as a unique thermal zone. This does not aim to reflect a real building with several thermally controlled zones. However, this model has already proven to 
be valid at first order at least, thus enough for energetic analysis. [16] However, it cannot be used for detailed thermal analysis of any buildings.
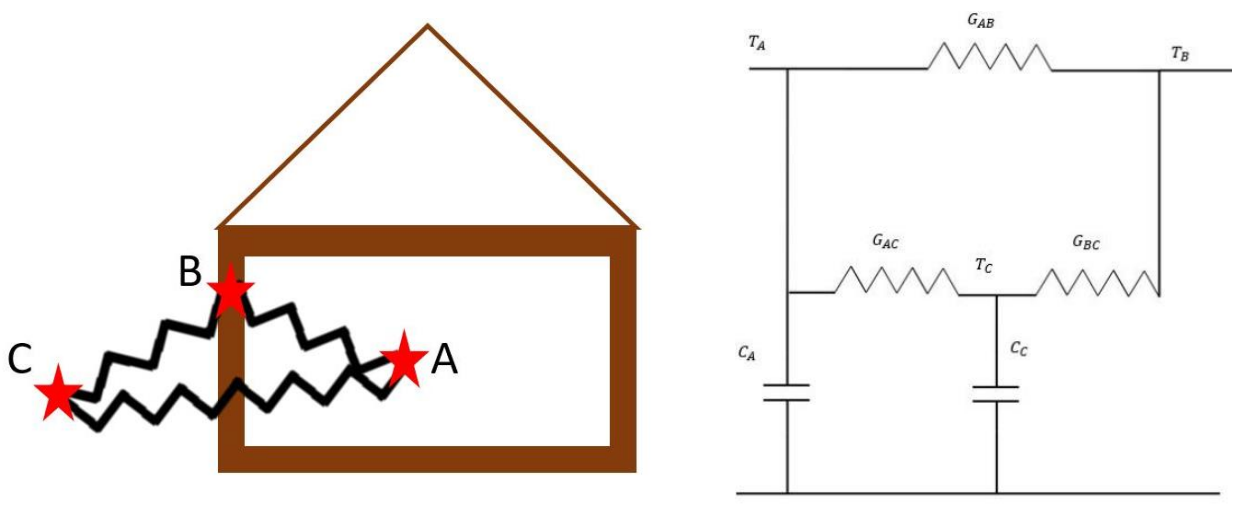

Figure 3: Two-node (or R3C2 model) thermal system representation of the building

This description is an adaptation of the one presented by Danza, Belussi, Meroni, Salamone, Floreani and Dabusti [16], which is inspired by Crabb, Murdoch and Penman[30]. This approach is classified as a dynamic thermal model by [31]. Other authors suggest their own adaptation by varying the number of equivalent resistance or capacitance [32], [33].

Point $A$ represents the ambient air inside the house, point $B$ describes the walls and point $C$ represents the external environment. For point $A$, the differential thermal equation that describes the system is computed by (6).

$$
\frac{d T_{A}}{d t}=\frac{\left(-G_{A B}+G_{A C}\right)}{C_{A}} T_{A}+\frac{G_{A B}}{C_{A}} T_{B}+\frac{P_{h e a t / A}}{C_{A}}+\frac{G_{A C}}{C_{A}} T_{C}
$$

with:

- $T_{A}, T_{B}$ and $T_{C}$ : ambient air, walls and external air temperature (K)

- $G_{A B}$ et $G_{A C}$ : respectively, the equivalent conductance between the inside air and the walls and between the inside air and the outside air. $(\mathrm{W} / \mathrm{K})$

- $C_{A}$ : heat capacity or thermal capacity, of the inside air $(\mathrm{J} / \mathrm{K})$

- $P_{\text {heat } / A}$ : heat given from a heater inside the room plus irradiance from the sun through glazing. 
The renewal of the inside air is included in the term $G_{A C}$ of conductance between the inside and outside air of the room. Moreover, the house is roughly represented simply as a large room.

The last equation can be easily applied to the two other points. These equations lead to a matrix system to solve (see Appendix B for more details).

The raw weather data provides the external ambient temperature $T_{C}$ throughout the year. Furthermore, the heat from the sun through the glazing of the house $S_{\text {gain }}$ can be postevaluated (a part of $P_{\text {heat } / A}$ and $P_{\text {heat } / B}$, [31]) and is fully presented in Appendix B. This approach can then provide the complementary heat that is needed to be provided through $P_{\text {heat } / A}$ to maintain an average temperature inside the house of at least 20 ㅇ C (that means we do not consider the energy consumption for cooling). An explicit resolution method is used to be sure there is no discrepancy in solving the equations.

For a specific case, the key parameters (equivalent conductance and heat capacity) of this kind of model need to be adjusted, so that the model can provide accurate results. To set these parameters, a tuning was performed to get an annual consumption per square meter in the Montreal area in the same order of magnitude to the country average (around 128 $\mathrm{kWh} / \mathrm{m}^{2} /$ year). This is only to fix the key parameters of the thermal model. Then these parameters remain fixed for all the other considered locations, for fair comparison purpose.

\subsubsection{Modelling of the different subsystems}

This section describes the calculations done by the GA for each hour throughout one year.

- Whole hydrogen system: 
As shown in Figure 1, the entire hydrogen system is composed of one DC-DC converter, an electrolyzer and a fuel cell, for which the rated power $P_{\text {elec }}$ and $P_{\text {fuel cell }}$ vary. There is additionally a storage system for the $\mathrm{H}_{2}$-tanks, with the number of tanks being an important design parameter. However, as the focus of this model is to analyse the energy flow, it is important to evaluate the SoC of the tank as well as the fuel cell and electrolyzer efficiency.

An alkaline electrolyser is considered due to its lower price compared to other technologies [34]. The efficiency of such an alkaline electrolyser is a function of the current density [35], as it is shown in Figure 4 (model extracted from [36]):

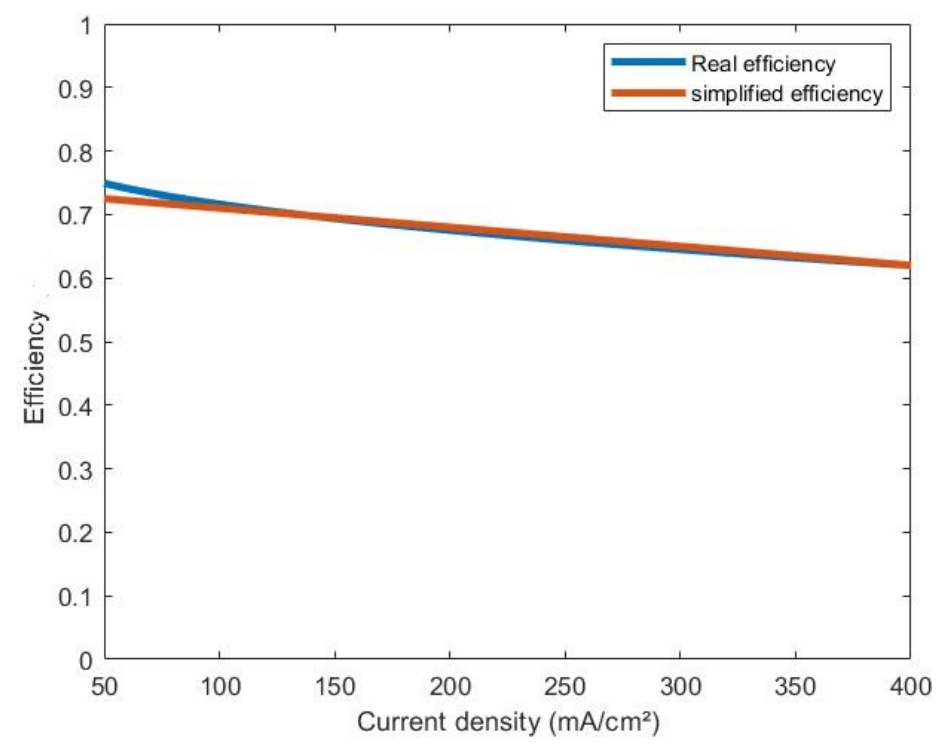

Figure 4: Real and simplified efficiency of the electrolyzer

Thus, considering the power supplied to the electrolyzer, the efficiency is considered a linearly decreasing function of power, assuming a fixed rated power (red curve in Figure 4). To convert a power supplied to the electrolyser into a quantity of hydrogen, the net calorific value of $\mathrm{H}_{2}$ (or low heating value) is used ( $L H V_{H_{2}} \approx 119930 \mathrm{~kJ} / \mathrm{kg}$.) This mass of $H_{2}$ is added or subtracted to the amount that is available in the tanks. To do so, the equation of state of Van der Waals is used (7): 


$$
\left(P+\frac{a n^{2}}{V^{2}}\right)(V-n b)=n R T
$$

with: $a \approx 0.0246 \mathrm{~Pa} . \mathrm{m}^{6} / \mathrm{mol}^{2}$ and $b \approx 0.00002655 \mathrm{~m}^{3} / \mathrm{mol}$. The storage temperature of $H_{2}$ is assumed to be constant, equal to $15^{\circ} \mathrm{C}$, and a 850 litre tank is assumed to have a maximum pressure of 60 bar [37]. The behaviour of the compressor is simplified to consider only a constant conversion efficiency of $95 \%$.

\section{- Battery system model:}

For this application, a Lithium-ion battery is considered. It is a $5 \mathrm{kWh}$ battery pack (24 V, $360 \mathrm{Ah}, 4 \mathrm{~m} \Omega$ and voltage slope $\delta=0.05 \mathrm{~V} / \%)$. The electrical model used is defined by following set of equations.

During the sizing, the number of batteries $N_{b a t}$ is varying. It is assumed that the batteries are connected in parallel to become a block of batteries, in order to maintain the output voltage. Thus, the resulting parameters of the block are:

$$
E_{\text {block }}=E_{\text {bat }} ; C_{\text {block }}=N_{\text {bat }} C_{\text {bat }} ; R_{\text {block }}=R_{\text {bat }} / N_{\text {bat }} ; V_{\text {bat }}=V_{\text {block }}
$$

with:

- $E_{\text {block }}$ : open circuit voltage of the pack of batteries (V).

- $C_{\text {block }}$ : nominal capacity of the pack of batteries (Ah).

- $R_{\text {block }}$ : internal resistance of the pack $(\Omega)$.

- $V_{\text {block }}$ : output voltage of the pack (V).

The maximum power that can be extracted from the block follows the equation [38]:

$$
P_{\text {bat_max }}=\frac{E_{\text {bat }}^{2}}{\left(4 R_{\text {bock }}\right)}
$$

That way, the current flowing through the batteries at a time $t$ is equal to: 


$$
I_{\text {block }, t}=\frac{E_{\text {bat }}-\sqrt{E_{\text {bat }}^{2}-4 R_{\text {block }} P_{\text {block }, t}}}{2 R_{\text {block }}}
$$

and the voltage can be evaluated using the equation:

$$
V_{\text {bat }}=E_{\text {bat }}-R_{\text {block }} I_{\text {block }}
$$

Finally, to manage properly the energy, the state of charge is needed and evaluated hour by hour using:

$$
S O C_{b a t, t}=S O C_{b a t, t-1}-\frac{I_{b l o c k, t}}{C_{b l o c k}}
$$




\section{Results and discussion}

\subsection{Solar resource estimation}

For each location, there is an optimal geometric position $(\beta, \gamma)_{\text {best }}$ that leads to the optimal solar production. Indeed, the solar production of the PV installation is a strong function of the mechanical position of the panels: the slope $\beta$ and the surface azimuth angle $\gamma$. This is shown in Figure 5, where these two angles are varying, and the annual PV production is scaled by the power of the installation presented. Tests have been conducted for the Montreal area and show that in order to maximize the solar energy produced, $\gamma \approx 0^{\circ}$ and $\beta \approx 30^{\circ}$ should be selected.

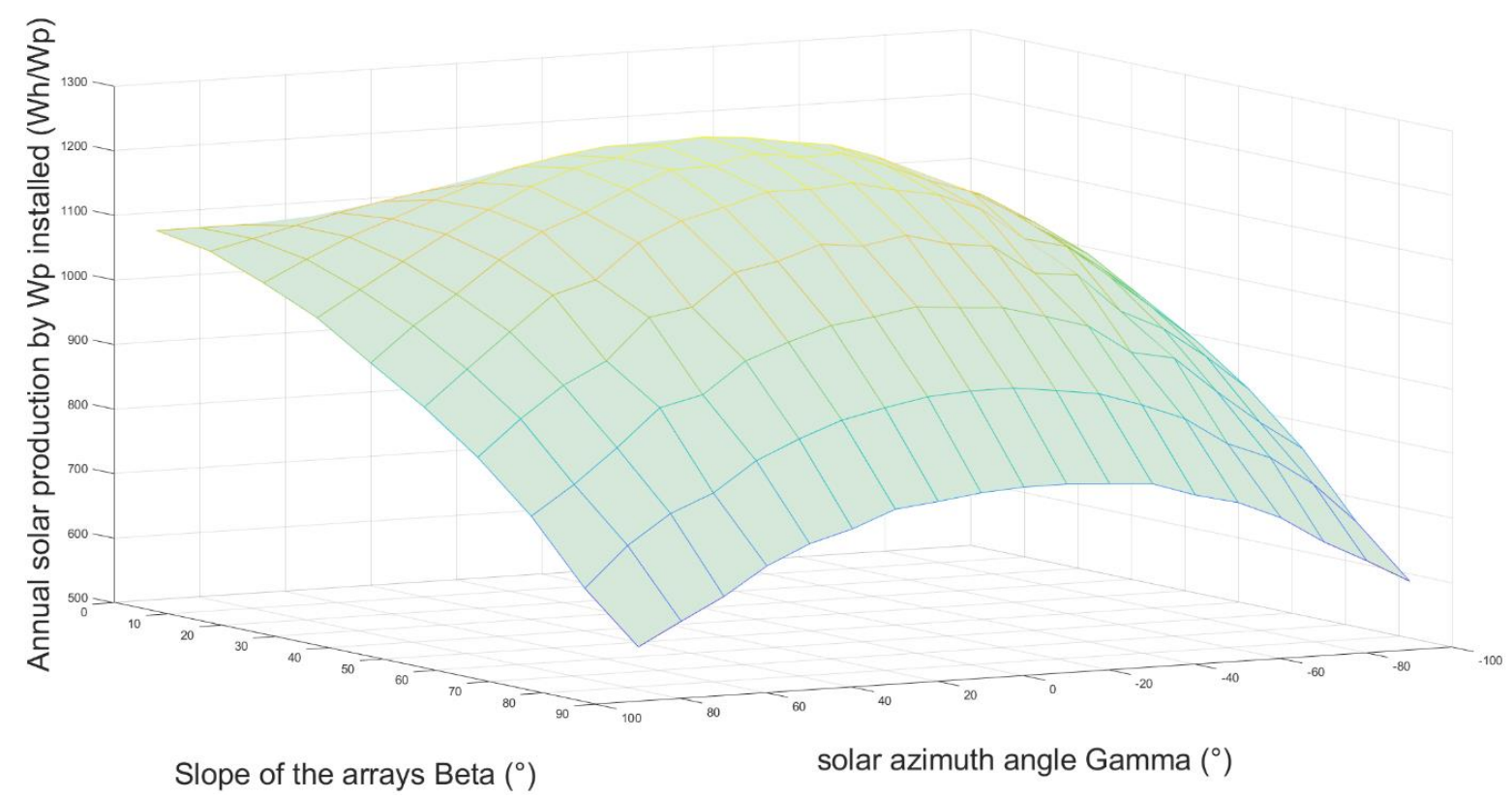

Figure 5: Annual PV production as a function of $\beta$ and $\gamma$ at the Montreal area 
Table 1 shows the annual solar energy produced at each area under consideration (Paris, Montreal, Moscow, Cairo and Hanoi), representing a wide range of different climates.

Table 1: Best annual solar production for the 5 places under study

\begin{tabular}{|c|c|c|c|c|}
\hline Local & Slope $\boldsymbol{\beta}\left(^{\circ}\right)$ & Azimuth $\gamma\left({ }^{\circ}\right)$ & $\begin{array}{c}\text { Annual production } \\
(\mathbf{k W h} / \mathbf{W p})\end{array}$ & $\begin{array}{c}\text { Relative gap (Montreal } \\
\text { area as reference) }\end{array}$ \\
\hline Montreal & 30 & 0 & 1.23 & $0 \%$ \\
\hline Cairo & 20 & 0 & 1.73 & $+41 \%$ \\
\hline Paris & 30 & 0 & 0.98 & $-20 \%$ \\
\hline Hanoi & 15 & 0 & 1.33 & $+8 \%$ \\
\hline Moscow & 30 & -10 & 0.91 & $-26 \%$ \\
\hline
\end{tabular}

This table highlights that the solar energy produced is a strong function of the location: the same arrays installed in Cairo will produce $41 \%$ more energy than the same ones if installed in the Montreal area. For the optimal sizing strategy using the GA, this best configuration is selected for each location. It is also interesting to notice that in order to optimize the PV production on the whole year, the arrays should in all cases face the South, which is in agreement with the fact that all the locations selected are in the Northern hemisphere, meaning that the sun is due South at the solar midday. Moreover, a link seems to appear between the latitude of the location and the best slope, as suggested by the Table 2 .

Table 2 : Angle between best slope and latitude of the location

\begin{tabular}{|c|c|c|c|}
\hline Local & Slope $\boldsymbol{\beta}\left({ }^{\circ}\right)$ & Latitude $\boldsymbol{\phi}\left({ }^{\circ}\right)$ & Difference $\left(^{\circ}\right)$ \\
\hline Montreal & 30 & 45 & 15 \\
\hline Cairo & 20 & 30 & 10 \\
\hline Paris & 30 & 49 & 19 \\
\hline Hanoi & 15 & 21 & 7 \\
\hline Moscow & 30 & 55 & 25 \\
\hline
\end{tabular}

Indeed, an angle of roughly $15^{\circ}$ should be deduce to the current latitude to give the optimal slope, if the climate is not too wet and foggy. However, for Hanoi, the diffuse radiation has a 
greater importance to the global solar radiation, meaning that the inclination of the arrays has minor impact on the resulting solar production.

Moreover, in the best configuration, the solar production fluctuates a lot throughout the year, as it is highlighted for the case of the Montreal area.

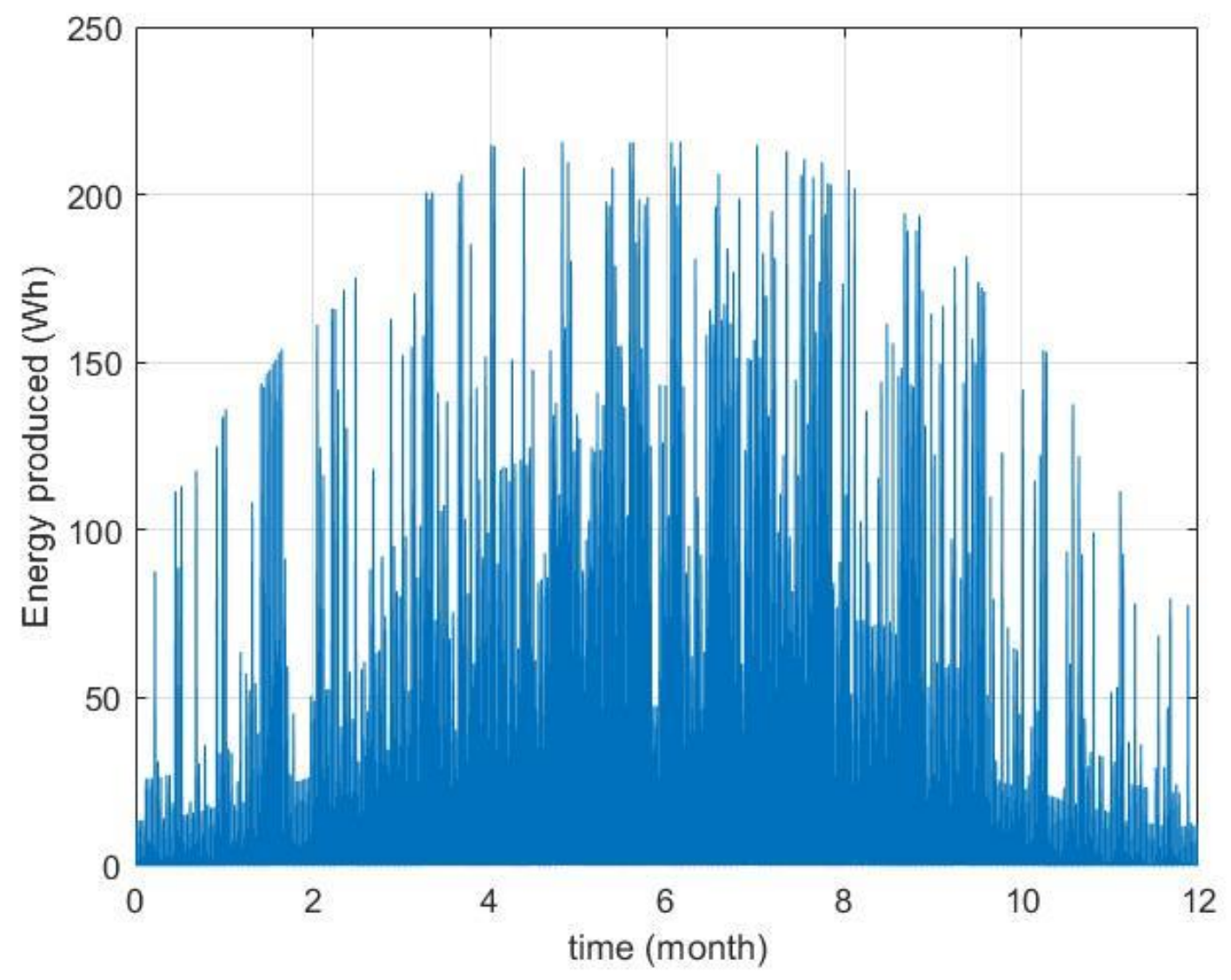

Figure 2 : Solar production throughout the year for the case of the Montreal area in optimal position

We clearly notice that the optimal configuration tends to maximize the production in Summer, while minimizing it in Winter. This will lead to a high need of energy storage, as explained in the following section. 


\subsection{Thermal demand of the building}

A specific building was used to create a thermal profile for each location. The features of the building are: a Living Area of $200 \mathrm{~m}^{2}$; thermal conductance $U$ of $0.25 \mathrm{~W} /\left(\mathrm{m}^{2} \mathrm{~K}\right)$ for the roof, 0.5 $\mathrm{W} /\left(\mathrm{m}^{2} \mathrm{~K}\right)$ for the walls and $6 \mathrm{~W} /\left(\mathrm{m}^{2} \mathrm{~K}\right)$ between the inside air and the walls. Building height is $6 \mathrm{~m}$ and the percentage of renewal air volume per hour is $n=30 \% / h$. These features give an annual consumption per square meter for the Montreal area in the same order of magnitude as the country average (around $128 \mathrm{kWh} / \mathrm{m}^{2}$ for heating in 2015, [39]).

The thermal response for the building under study in the Montreal area is presented in Figure 6. Note that this is a 3D map, where the colours are used to better appreciate the graph. 


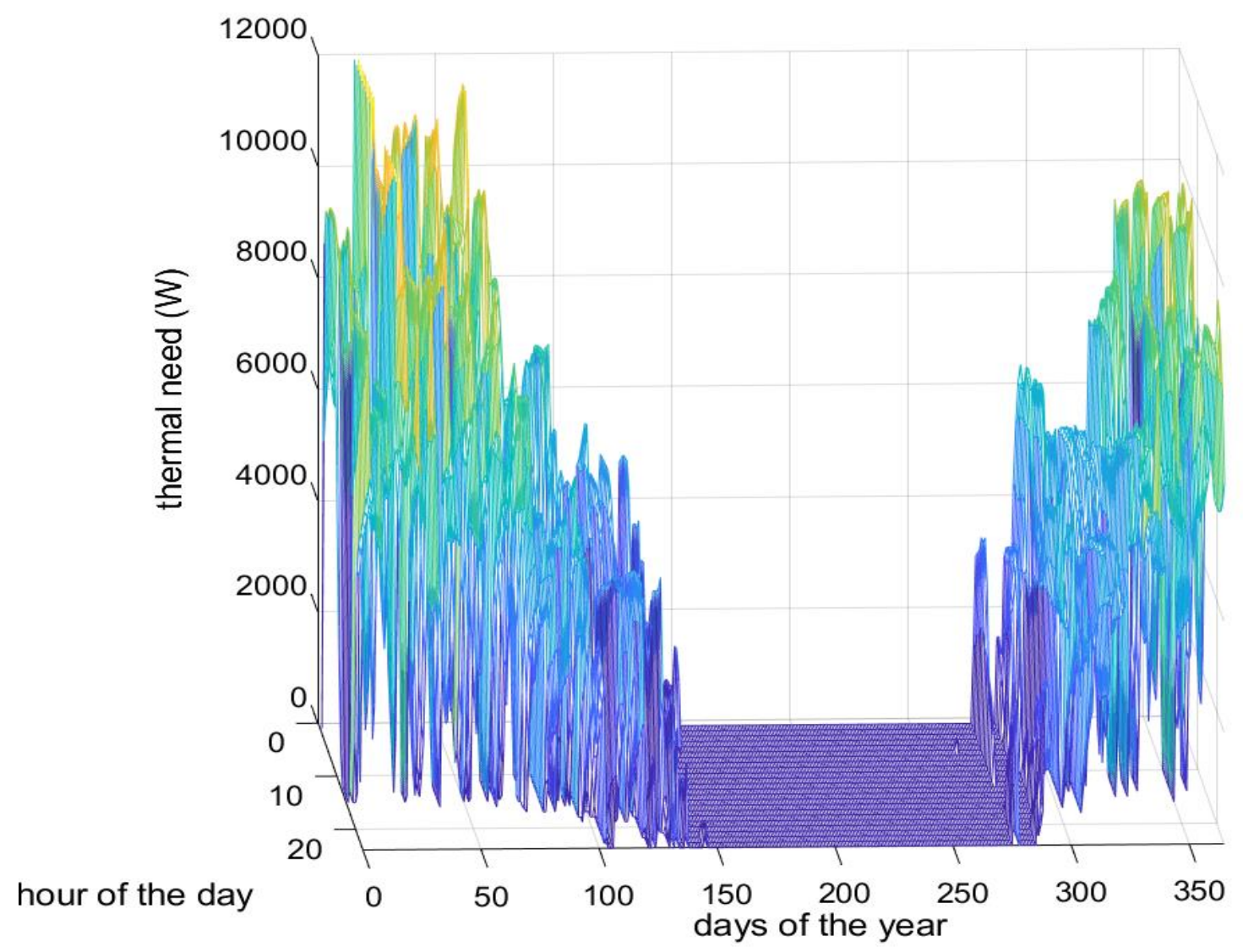

Figure 6: Thermal demand throughout the year in the Montreal area

Figure 6 highlights clearly the seasonal impact of the local climate on the thermal demand of the house. This seasonal impact is consistent with more specific studies presented in [32]. We can notice a high thermal demand between November and March, with pic values in January. However, during that period, the PV production is also low compared to what can be produced in Summer. Since the higher thermal needs occur when the solar energy production is low, the stand-alone system must store a huge amount of energy to face these periods.

A summary of the annual consumption for heating at the different locations is presented in Table 3. 
Table 3: Annual consumption for heating for the 5 areas under study

\begin{tabular}{|c|c|c|}
\hline Place & Annual consumption for heating $\left(\mathrm{kWh} / \mathrm{m}^{2} /\right.$ year) & $\begin{array}{c}\text { Relative gap (Montreal area as } \\
\text { reference) }\end{array}$ \\
\hline Montreal & 121.3 & $0 \%$ \\
\hline Cairo & 1.35 & $-99 \%$ \\
\hline Paris & 70.6 & $-41.8 \%$ \\
\hline Hanoi & 3.8 & $-97 \%$ \\
\hline Moscow & 139.3 & $+14.8 \%$ \\
\hline
\end{tabular}

Results highlight the primary impact of the local climate on the heating consumption of the building. Indeed, with the same building and simply by changing the environment with solar input that warms the building and the exterior temperature, the annual consumption fluctuates from almost $100 \%$ from a place to another. This heating consumption could thus become negligible compared to an average electrical consumption of $85 \mathrm{kWh} / \mathrm{m}^{2} /$ year for warm places like Cairo or Hanoi, as well as it can also be of paramount importance for cold places like the Montreal or Moscow area.

Note that cooling is not considered here since air conditioning efficiency is much higher than heating element efficiency. Besides, there are many passive ways to limit the warming of a building by the sun, like the use of cheap overhangs and wingwalls to shade the windows.

\subsection{Optimal Sizing for the different locations}

To size the energy systems, the different research spaces are set as shown in Table 4.

Table 4: Range of variation and price of the parameters used for the sizing procedure 


\begin{tabular}{|c|c|c|}
\hline Element & Range of variation & price \\
\hline Battery (5kWh) & 1 to 15 , by step of 1 & 380 USD\$/kWh \\
\hline PV arrays (250 Wp) & 1 to 500 , by step of 1 & 2800 USD\$/kWp (total installation) \\
\hline Max power of electrolyzer & 1 to $50 \mathrm{~kW}$, by step of $0.5 \mathrm{~kW}$ & 1500 USD\$/kW \\
\hline Max power of the fuel cell & 1 to $50 \mathrm{~kW}$, by step of $0.5 \mathrm{~kW}$ & 1500 USD\$/kW \\
\hline Number of $\mathrm{H}_{2}$-tanks $\left(0.85 \mathrm{~m}^{3}\right)$ & 1 to 200 , by step of 1 & 10 USD\$/kWh \\
\hline
\end{tabular}

The prices selected are in magnitude what is available nowadays. For the $H_{2}$-tanks, [40] propose to use around 6 USD $\$ / \mathrm{kWh}$, whereas it is rather $10 \mathrm{USD} \$ / \mathrm{kWh}$ in [41]. The alkaline electrolyzer's price is around 1500 USD\$/kW as suggested by [34]. For the batteries, the market is moving quickly but 380 USD\$/kWh is in agreement with [42]. Eventually for the fuel cells, price is highly function of the size of the system itself, but 1500 US\$/kW seems to be reachable in most of the cases [42].

The electrical consumption (excluding heating) of the house is set to $85 \mathrm{kWh} / \mathrm{m}^{2} /$ year regardless of the location. This is an average consumption, including domestic hot water, cooling, lighting and household appliances. This consumption is mapped throughout the year using the profile of normalized French residence available from ENEDIS [43], presented in Figure 3. 


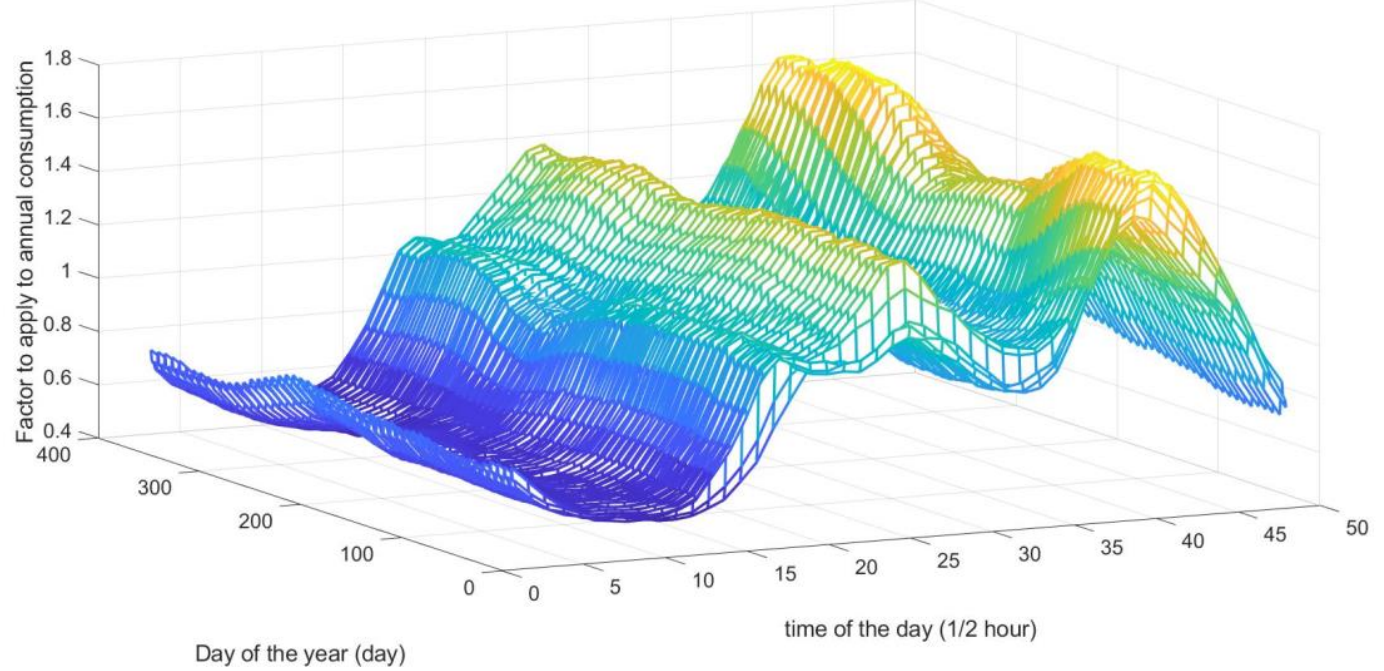

Figure 3 : Profile of normalized French residence

The sizing results for the Montreal area are presented in Figure 7.

\begin{tabular}{|r|c|}
\hline \multicolumn{1}{|c|}{ Place } & Montreal \\
\hline Electrical consumption (MWh/year) & 17 \\
\hline Thermal consumption (MWh/year) & 25.2 \\
\hline Total consumption (MWh/year) & 42.2 \\
\hline Solar production (kWh/Wp/year) & 1.2 \\
\hline PV installed power (kWp) & 45.5 \\
\hline Batteries capacity (kWh) & 55 \\
\hline Total tank capacity (kWh) & 8720 \\
\hline Energy reserve (equiv. week/Total annual need) & 10.7 \\
\hline Electrolyzer rated power (kW) & 22.5 \\
\hline Fuel cell rated power (kW) & 5 \\
\hline Total cost of the whole system (kUSD\$) & 345.4 \\
\hline
\end{tabular}

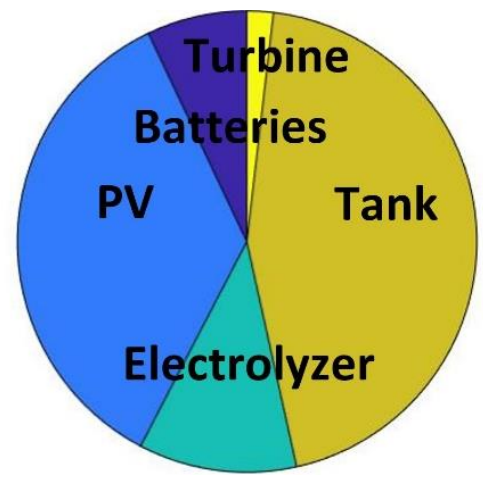

Figure 7 - Results of the sizing using GA of the stand-alone system implanted in the Montreal area

The results lead to a very expensive global system, essentially due to a very high capacity of energy storage. We define the energy reserve as: 


$$
\text { Energy Reserve }(\text { weeks })=52 \frac{\text { Tank capacity }}{\text { Total annual need }}
$$

Considering the case of the Montreal area, the energy reserve request is above 10.7 weeks. This highlights the seasonal impact of the climate that leads to a high storage capacity requirement. This also suggests that the thermal need of the house should be reduced, by developing better thermal resistance of the building to reduce the overall system cost. The SoC for the batteries and the tanks are represented in Figure 8. The batteries have an average SoC of $57 \%$ but are used heavily throughout the year. The $\mathrm{H}_{2}$-SoC reveals the seasonal impact of the climate, with a period of global deficit during the winter, resulting in a continuous decrease of hydrogen stored in the tanks. 

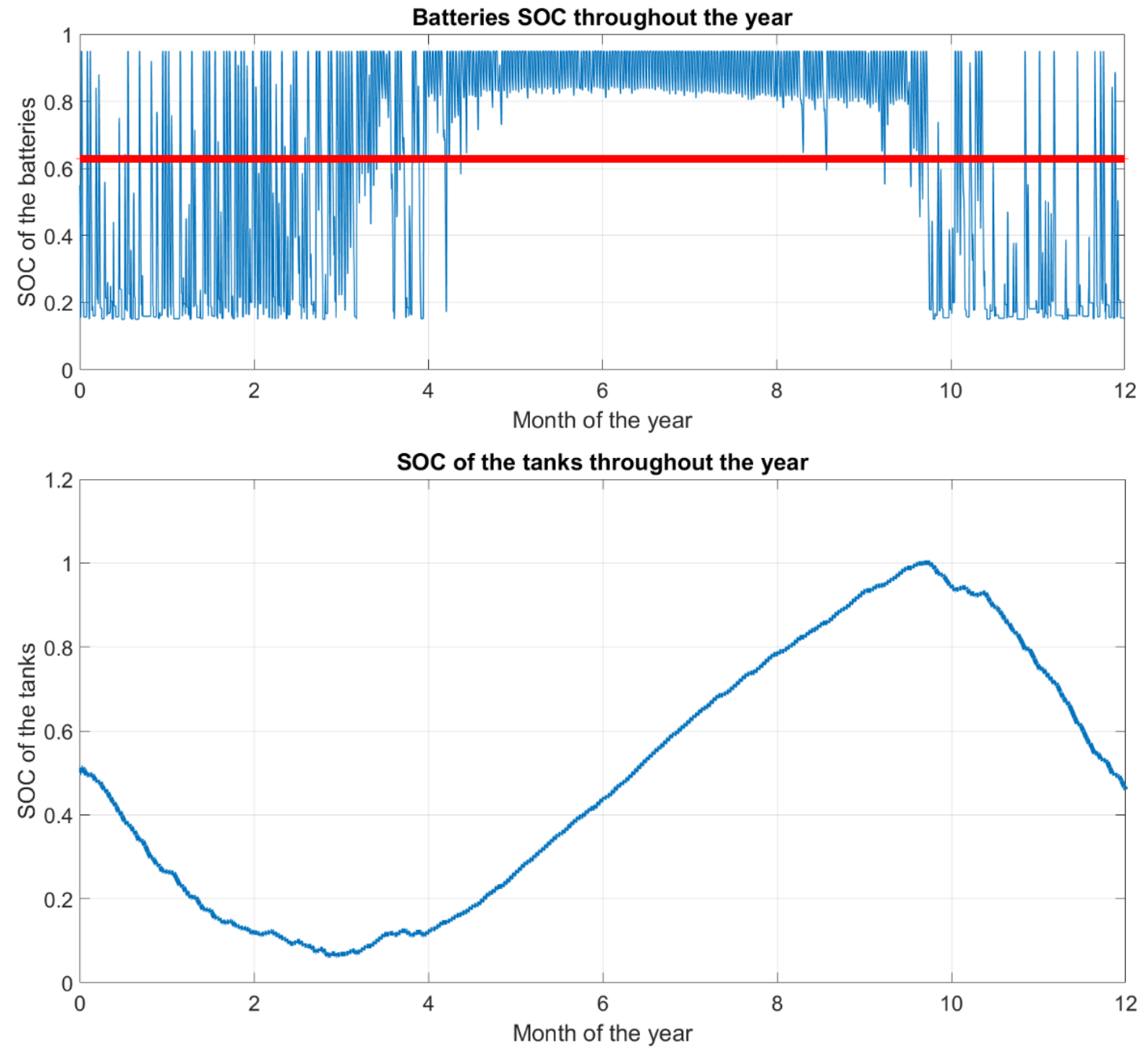

Figure 8: SoC of the batteries and the tanks throughout the year

This is interesting to notice the sinusoidal variation of the $\mathrm{H}_{2}$-SoC throughout the year, which has not been superimposed but is the result of the optimal sizing provided by the GA. We should also observe the daily scale of variation of the batteries $\mathrm{SoC}$, which is also a consequence of the optimal sizing.

To validate that the sizing is almost optimal in the case under study, a verification procedure has been developed. For verification, the optimization procedure was repeated ten times and the results were saved and compared. Fixing $L P S P=0.05$, the ten solutions returned by GA are 
grouped, with a maximum relative gap of $1.4 \%$ (with the best solution as a reference). The results are presented for the case of the Montreal and Paris area in Table 5.

Table 5: Repetition of the optimization routine

\begin{tabular}{|c|c|c|}
\hline Test & $\begin{array}{c}\text { Montreal: Final penalty } \\
\text { function (USD } \mathbf{k} \text { ) }\end{array}$ & $\begin{array}{c}\text { Paris: Final penalty } \\
\text { function (USD k\$) }\end{array}$ \\
\hline $\mathbf{1}$ & 346.2 & 300.5 \\
\hline $\mathbf{2}$ & 345.45 & 299.82 \\
\hline $\mathbf{3}$ & 348.75 & 301.34 \\
\hline $\mathbf{4}$ & 350.34 & 302.45 \\
\hline $\mathbf{5}$ & 348.09 & 302.15 \\
\hline $\mathbf{6}$ & 346.95 & 298.87 \\
\hline $\mathbf{7}$ & 346.54 & 300.0 \\
\hline $\mathbf{8}$ & 348.29 & 302.56 \\
\hline $\mathbf{9}$ & 345.93 & 298.87 \\
\hline $\mathbf{1 0}$ & 347.31 & 301.65 \\
\hline
\end{tabular}
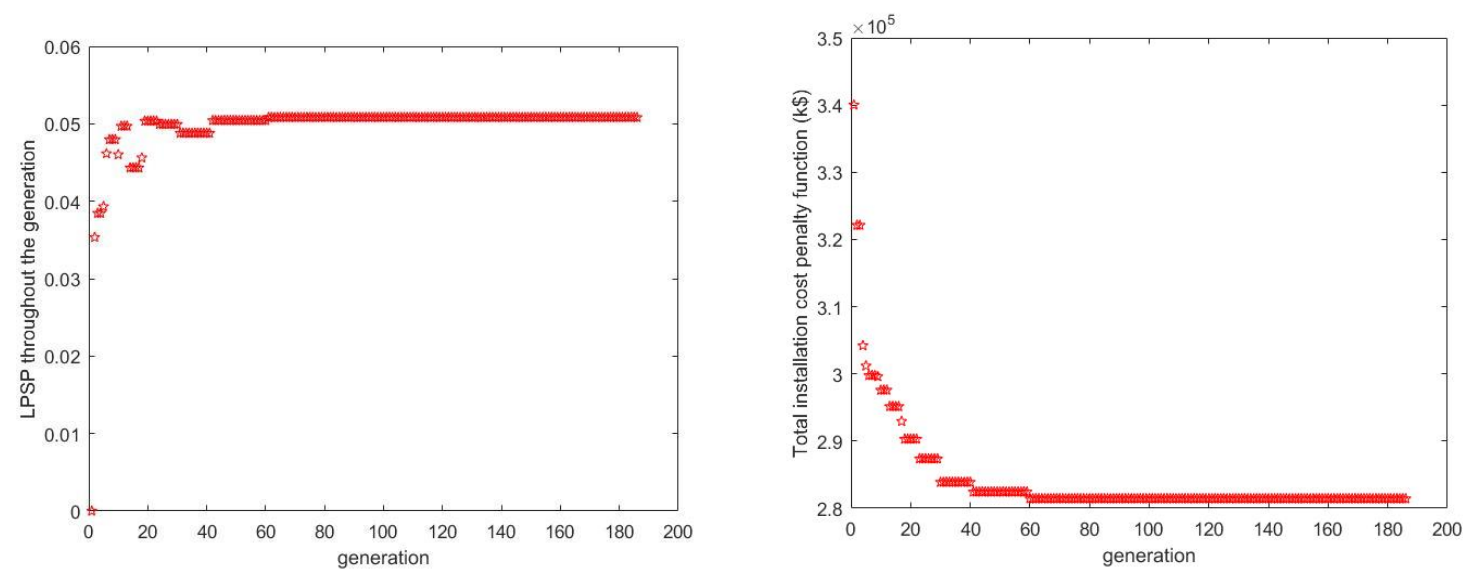

Figure 4 : LPSP and Total installation cost throughout the generation (Montreal)

Throughout the generation, the optimal individual is presented above for the optimal sizing obtained. It is shown quite obviously that as the price is decreasing, the LPSP is increasing, but remains just under the maximum target of 0.05 . 
The same methodology is used for the other locations and the key parameters for the sizing obtained by the GA are summarized in Table 6 .

Table 6: Compared sizing results for different locations using GA.

\begin{tabular}{|r|c|c|c|c|c|}
\hline \multicolumn{1}{|c|}{ Place } & Montreal & Cairo & Paris & Hanoi & Moscow \\
\hline Electrical consumption (MWh/year) & 17 & 17 & 17 & 17 & 17 \\
\hline Thermal consumption (MWh/year) & 25.2 & 0.3 & 14.7 & 0.8 & 28.7 \\
\hline Total consumption (MWh/year) & 42.2 & 17.3 & 31.7 & 17.8 & 45.7 \\
\hline Solar production (kWh/Wp/year) & 1.2 & 1.7 & 1 & 1.3 & 0.9 \\
\hline PV installed power (kWp) & 45.5 & 14.8 & 44.8 & 21.5 & 68.3 \\
\hline Batteries capacity (kWh) & 55 & 25 & 60 & 20 & 55 \\
\hline Total tank capacity (kWh) & 8720 & 400 & 6800 & 1200 & 12480 \\
\hline Energy reserve (equiv. week/Total annual need) & 10.7 & 1.2 & 11.2 & 3.5 & 14.2 \\
\hline Electrolyzer rated power (kW) & 22.5 & 1 & 16 & 6.5 & 32.5 \\
\hline Fuel cell rated power (kW) & 5 & 1 & 3.5 & 1 & 5 \\
\hline Total cost of the whole system (kUSD) & $\mathbf{3 4 5 . 4}$ & $\mathbf{6 0 . 9}$ & $\mathbf{2 9 8 . 9}$ & $\mathbf{1 0 0 . 5}$ & $\mathbf{4 9 1 . 3}$ \\
\hline Relative gap (Montreal=reference) & $\mathbf{0 \%}$ & $\mathbf{- 8 2 . 4 \%}$ & $\mathbf{- 1 3 . 5 \%}$ & $\mathbf{- 7 0 . 9 \%}$ & $\mathbf{+ 4 2 . 2} \%$ \\
\hline
\end{tabular}

The GA sizing coupled with the proposed methodology reveals that the climate has a huge impact on the total cost of the system. For the climates with a harsh winter (Montreal, Paris, Moscow), the sizing reveals a need for about 10 weeks of energy reserve in order to overcome the winter energy demands. This energy reserve appears quasi-constant for the areas of Paris, Montreal and Moscow, whereas the tank capacity and the thermal consumption for these locations vary from almost $100 \%$. Thus, the parameter introduced seems to be relevant and can allow a fast sizing of the system knowing for instance the thermal consumption. Moreover, in term of the repartition of each key element on the total price, these tough climates result in an optimal system that has the same features, as it is shown in Figure 9. 


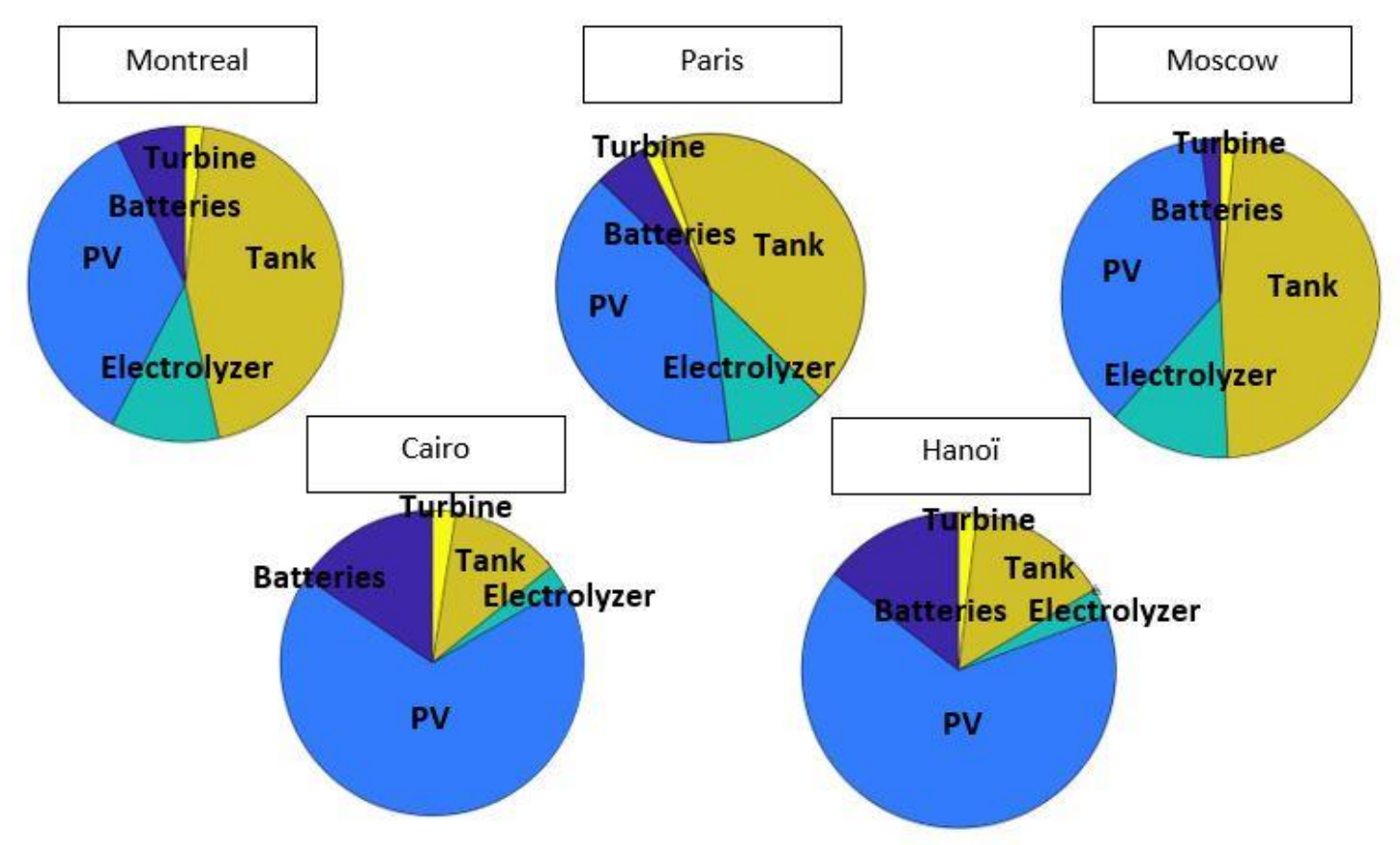

Figure 9: Visualization of the total cost breakdown for each place

We can thus remark that the PV arrays and the tanks cover more than two third of the global price. This directly results in a much higher cost compared to the places where there is no need for an energy reserve, like Hanoi and Cairo. However, even for these tough climates, a huge variation still exists, depending on the degree of severity of the climate (from 299 kUSD\$ in Paris up to 491 kUSD\$ in Moscow). Moreover, for warm climates, the optimal solution seems to converge towards another constant configuration, where the PV system weighs for around $3 / 4$ of the total installation price, and the lasting part is equally distributed between the battery system on one hand, and the fuel cell, tanks and electrolyzer on the other hand. Thus, when there is not a big need for energy storage, the PV system remains the most expensive part of the system. These results suggest that some places are much more suitable for the developing of stand-alone systems than others. The results also suggest work should be done to reduce the thermal need of the buildings, or to find a way to reduce the resulting high cost 
of storage systems. Another possibility is the hybridization of the considered system with a wind fuel cell or trying to use heat pump that can multiply the thermal energy available by its high efficiency. Unfortunately, these systems (heat pump or fuel cell) currently have high cost. Also, a gas boiler to partially heat the building can be considered, but its impact should be validated. 


\section{Conclusion}

This paper has presented a sizing method using a GA to implement a stand-alone hybrid system while minimizing the total cost of the system. Thanks to the proposed global approach, the sizing can be adjusted for different locations worldwide in a systematic way.

The analysis of 5 locations with different climatic conditions highlights that some places are much more suitable for developing stand-alone buildings than others. Considering the Montreal area as a reference, the same autonomous building will be $44 \%$ more expensive in Moscow and more than $80 \%$ cheaper if implemented in Cairo. This is due to the local climate, which modifies the solar resource and thermal need of the building. Also, a solar panel in its best orientation will produce $40 \%$ more electricity in Cairo and $25 \%$ less electricity in Moscow. Additionally, the same building will need around 99\% less energy for heating in Cairo and almost $15 \%$ more energy in Moscow.

The model also highlighted that for cold climates, the thermal need during the winter is the major contributor to the cost of the stand-alone system. In such cases, proper insulation of the house is of paramount importance to enable a stand-alone building to be efficient.

This study is a first step towards the implementation of a stand-alone building that considers the climatic conditions of the location. Once a system is sized, it is then necessary to develop a real-time energy management strategy, that controls the energy flows between the different subsystems. Work on this is underway. 


\section{Acknowledgements}

This work was supported by the LN2, which is a joint International Research Laboratory (Unité Mixte de Recherche UMI 3463) funded and co-operated by Université de Sherbrooke (Canada), CNRS (France) as well as INSA Lyon, ECL, CPE, Université Joseph Fourier and the French national nanofabrication network, RENATECH , and, also, partially supported by European Regional Development Fund through the COMPETE 2020 Program and the Portuguese FCT within projects ESGRIDS (POCl-01-0145-FEDER-016434) and MAnAGER (POCl-01-0145-FEDER028040), and FCT under project grant UID/MULTI/00308/2019. We finally acknowledge the support of the Natural Sciences and Engineering Research Council of Canada (NSERC), [funding reference number 497981].

\section{Appendix A: Compared analysis on the orientation of the panels}

In the previous results, the configuration that maximises the annual PV production has been chosen. This resulted in a production that is maximized during the summer, when there is no significant thermal need. However, one may suggest that a configuration that conduct to maximize the PV production during winter, in order to better fit with the need of the building. Indeed, by tilting the arrays a little bit more, the production is at its highest level in winter and lowest level in summer, as presented in Figure 11. 

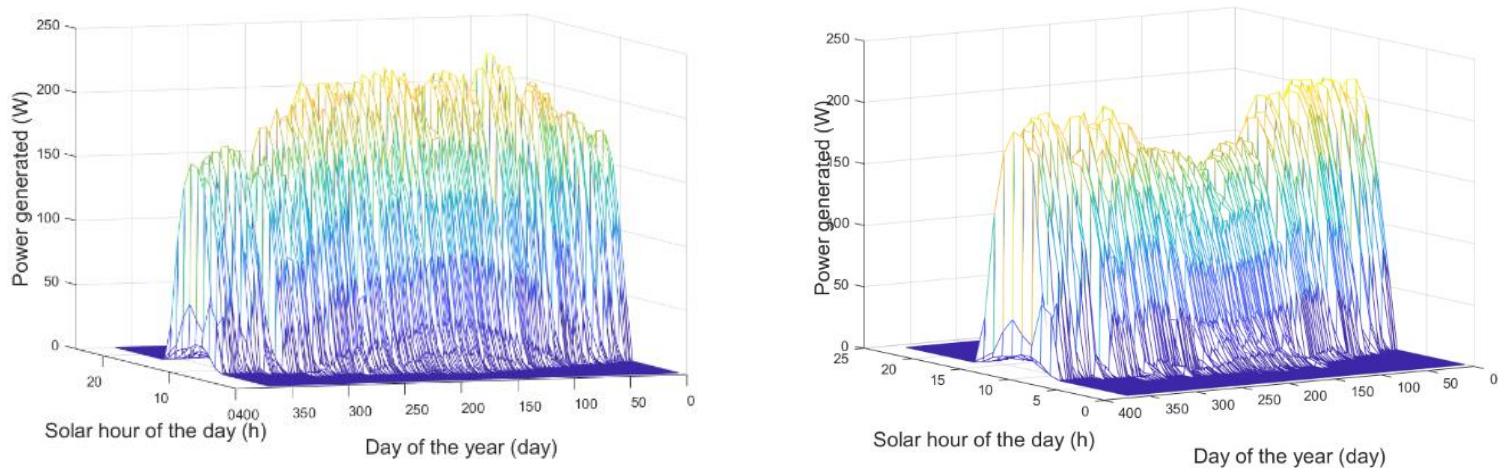

Figure 11: Solar production for one array in the Montreal area tilted towards south at: $70^{\circ}$

(right) and $30^{\circ}$ (left)

However, at $\beta \approx 70^{\circ}$, the annual solar production is much lower than the production expected for $\beta \approx 30^{\circ}$ : that represents $15.45 \%$ less of annual solar production. This finally leads to a total installation cost that is a slightly higher, even if there is a better match between the PV production and the global requirement of the building, as presented in Table 7.

Table 7: Compared result for two different configurations of the arrays

\begin{tabular}{|r|c|c|}
\hline Montreal, solar azimuth angle $\gamma=\mathbf{0}^{\circ}$ & $\boldsymbol{\beta}=30^{\circ}$ & \multicolumn{1}{|c|}{$\boldsymbol{\beta}=\mathbf{7 0}^{\circ}$} \\
\hline Electrical consumption (MWh/year) & 17 & 25.2 \\
\hline Thermal consumption (MWh/year) & 25.2 & 42.2 \\
\hline Total consumption (MWh/year) & 42.2 & 1 \\
\hline Solar production (kWh/Wp/year) & 1.2 & 52.8 \\
\hline PV installed power (kWp) & 45.5 & 55 \\
\hline Batteries capacity (kWh) & 55 & 7920 \\
\hline Total tank capacity (kWh) & 8720 & 9.7 \\
\hline Energy reserve (equiv. week/Total annual need) & 10.7 & 24.5 \\
\hline Electrolyzer rated power (kW) & 22.5 & 5 \\
\hline Fuel cell rated power (kW) & 5 & 354.4 \\
\hline
\end{tabular}


However, the results highlight a possibility for the design of the installation: with a different geometric configuration of PV arrays, which provides a higher production during the winter, the price increases very slightly, but the total volume of $H_{2}$-tanks decreases.

\section{Appendix B: Thermal matrix system and evaluation of the solar gain}

Considering, the thermal matrix system:

$$
\frac{d \vec{T}}{d t}=\vec{A} \vec{T}+\vec{B} \vec{U}
$$

with: $\vec{T}=\left(\begin{array}{c}T_{A} \\ T_{B}\end{array}\right) ; \bar{A}=\left(\begin{array}{cc}-\frac{G_{A B}+G_{A C}}{C_{A}} & \frac{G_{A B}}{C_{A}} \\ \frac{G_{A B}}{C_{B}} & -\frac{G_{A B}+G_{B C}}{C_{B}}\end{array}\right) ; \vec{U}=\left(\begin{array}{c}P_{\text {heat } / A} \\ P_{\text {heat } / B} \\ T_{C}\end{array}\right) ; \bar{B}=\left(\begin{array}{ccc}1 / C_{A} & 0 & G_{A C} / C_{A} \\ 0 & 1 / C_{B} & G_{B C} / C_{B}\end{array}\right)$

To present it, it is necessary to fix some parameters of the building:

- Areas of glazing:

$$
A_{g, \text { north }}=3 m^{2} ; A_{g, \text { south }}=25 m^{2} ; A_{g, \text { east }}=8 m^{2} ; A_{g, \text { west }}=7 \mathrm{~m}^{2} ; A_{g, \text { total }}=\sum_{i=1}^{4} A_{g, i}
$$

- Glass features: Thermal conductance $U_{\text {glass }}=2.6 \mathrm{~W} /\left(\mathrm{m}^{2} \mathrm{~K}\right)$; Extinction coefficient $\mathrm{K}=15$ $m^{-1}$, thick e=3.5mm and number of panes $n_{\text {panes }}=2$.

To evaluate the solar radiation that crosses each glazing, it is proposed to adapt a method from [26]. For each area of glass, the incidence angle $\theta_{1}$ of the direct radiation is evaluated, then the absorption and transmission coefficient are calculated for that angle, using (16):

$$
n_{1} \cdot \sin \left(\theta_{1}\right)=n_{2} \cdot \sin \left(\theta_{2}\right) \quad\left(n_{1}=1 \text { for air, } n_{2}=1.526 \text { for glass }\right)
$$

- Transmission coefficient for absorption: 


$$
\tau_{\alpha}=\frac{I_{\text {transmitted }}}{I_{\text {incident }}}=e^{\left(\frac{-K \cdot L \cdot n_{\text {panes }}}{\cos \left(\theta_{2}\right)}\right)}
$$

- Transmission coefficient for reflection:

$$
\tau_{r}=\frac{1}{2} \cdot\left(\frac{1-r_{/ /}}{1+\left(2 \cdot n_{\text {panes }}-1\right) \cdot r_{/ /}}+\frac{1-r_{\perp}}{1+\left(2 \cdot n_{\text {panes }}-1\right) \cdot r_{\perp}}\right)
$$

with: $r_{/ /}=\frac{\tan ^{2}\left(\theta_{2}-\theta_{1}\right)}{\tan ^{2}\left(\theta_{2}+\theta_{1}\right)}$ the parallel component of unpolarized radiation and $r_{\perp}=\frac{\sin ^{2}\left(\theta_{2}-\theta_{1}\right)}{\sin ^{2}\left(\theta_{2}+\theta_{1}\right)}$ the perpendicular component of unpolarized radiation.

For the diffuse and reflected radiation, an equivalent angle $\theta_{1, \text { equiv }}$ is used from the depicted approach in [44].

The average absorption of the house is evaluated using the equation:

$$
\alpha_{\text {real,room }}=\frac{\alpha_{\text {room }}}{\alpha_{\text {room }}+\left(1-\alpha_{\text {room }}\right) \cdot \tau_{d} \cdot A_{\text {g,total }} /\left(A_{\text {room }}-A_{\text {g,total }}\right)}
$$

with $\alpha_{\text {room }}=0.45$ average absorption coefficient of the inner walls, $A_{\text {room }}$ total inner areas of all the walls $\left(\mathrm{m}^{2}\right)$ and $\tau_{d}$ average transmission coefficient for the diffuse radiation of the room.

For each facade of the building, as it is done for the solar resource estimation, the direct, diffuse and reflected radiation need to be evaluated separately:

$$
\begin{aligned}
S_{\text {gain,North }}= & I_{r, \text { north }} \cdot R_{b} \cdot \alpha_{\text {real,room,direct }} \cdot \tau_{\alpha, \text { direct }} \cdot \tau_{r, \text { direct }}+I_{d, \text { north }} \\
& \cdot\left(\frac{1+\cos (\beta)}{2}\right) \cdot \alpha_{\text {real,room,diffuse }} \cdot \tau_{\alpha, \text { diffuse }} \cdot \tau_{r, \text { diffuse }} \\
& +I \rho_{s}\left(\frac{1-\cos (\beta)}{2}\right) \cdot \alpha_{\text {real,room,albedo }} \cdot \tau_{\alpha, \text { albedo }} \cdot \tau_{r, \text { albedo }}
\end{aligned}
$$


Eventually, the radiation collected by the building is obtained using (21):

$$
S_{\text {gain }}=S_{\text {gain,North }}+S_{\text {gain,South }}+S_{\text {gain,East }}+S_{\text {gain }, \text { West }}
$$

The radiation can be evaluated hourly throughout the year based on the energy coming from the sun and collected by the building. These equations can be solved to get the annual thermal demand of the house.

\section{Appendix C: Efficiency of the PV solar panels}

The efficiencies $\eta_{m p p t}$ and $\eta_{\text {elec }}$ are estimated using the following equations:

$$
\begin{gathered}
\eta_{m p p t}=\eta_{m p_{\text {ref }}} *\left\{1-\frac{\mu_{m p}}{\eta_{m p_{\text {ref }}}} *\left(T_{a}-T_{r}\right)-\mu_{m p} * \frac{\tau \alpha * I_{t}}{U * \eta_{m p_{r e f}} * 3600} *\left(1-\eta_{m p_{\text {ref }}}\right) * Z i\right\} \\
\eta_{\text {elec }}=\eta_{i} * k_{I A M} *\left(1-P_{S}-P_{M}-P_{O}-P_{P}\right)
\end{gathered}
$$

With:

$\eta_{m p \_r e f}:$ the rated efficiency of the solar panel at its MPPT point (manufacturer's data)

$\mu_{m p}$ : temperature coefficient at the MPPT point (manufacturer's data)

$T_{a}$ and $T_{r}$ : respectively, ambient and reference $\left(=25^{\circ} \mathrm{C}\right)$ temperature

$U$ : global heat transfer coefficient, $\mathrm{U} \approx 800 * \tau \alpha /\left(T_{\text {NOTC }}-20\right)$, with $T_{\text {NOTC }}$ corresponding to the fixed temperature of the cell in standard condition $\left({ }^{\circ} \mathrm{C}\right)$

$Z i$ : intermediate calculation (see : [26])

$\eta_{i}$ : efficiency of the DC-DC converter

$k_{I A M}$ : incidence angle modifier 
$P_{s}, P_{M} P_{p}$ and $P_{O}:$ dust loss $(0.2 \%)$, deviation between real and specified operation (3\%), loss due to deviation between real and standard I/V curves (2\%), and ohmic loss (0.4\%). 


\section{References}

[1] B.K. Das, Y.M. Al-Abdeli, G. Kothapalli, Optimisation of stand-alone hybrid energy systems supplemented by combustion-based prime movers, Appl. Energy. 196 (2017) 18-33. doi:10.1016/j.apenergy.2017.03.119.

[2] Agency IE, Energy access database, World Energy Outlook 2017, (n.d.). http://www.iea.org/weo2017/\#section-2-3 (accessed July 20, 2018).

[3] D. Feldman, G. Barbose, R. Margolis, Photovoltaic System Pricing Trends, U.S. Department of Energy, 2015. https://www.nrel.gov/docs/fy 15osti/64898.pdf.

[4] M. Salvador, S. Grieu, Methodology for the design of energy production and storage systems in buildings: Minimization of the energy impact on the electricity grid, Energy Build. 47 (2012) 659-673. doi:10.1016/j.enbuild.2012.01.006.

[5] H. Karunathilake, K. Hewage, W. Mérida, R. Sadiq, Renewable energy selection for netzero energy communities: Life cycle based decision making under uncertainty, Renew. Energy. 130 (2019) 558-573. doi:10.1016/j.renene.2018.06.086.

[6] R. Hemmati, H. Saboori, Stochastic optimal battery storage sizing and scheduling in home energy management systems equipped with solar photovoltaic panels, Energy Build. 152 (2017) 290-300. doi:10.1016/j.enbuild.2017.07.043.

[7] B. Li, R. Roche, D. Paire, A. Miraoui, Sizing of a stand-alone microgrid considering electric power, cooling/heating, hydrogen loads and hydrogen storage degradation, Appl. Energy. 205 (2017) 1244-1259. doi:10.1016/j.apenergy.2017.08.142.

[8] H. Yang, W. Zhou, L. Lu, Z. Fang, Optimal sizing method for stand-alone hybrid solarwind system with LPSP technology by using genetic algorithm, Sol. Energy. 82 (2008) 354-367. doi:10.1016/j.solener.2007.08.005.

[9] D. Abbes, A. Martinez, G. Champenois, Life cycle cost, embodied energy and loss of power supply probability for the optimal design of hybrid power systems, Math. Comput. Simul. 98 (2014) 46-62. doi:10.1016/j.matcom.2013.05.004.

[10] R. Wang, G. Li, M. Ming, G. Wu, L. Wang, An efficient multi-objective model and algorithm for sizing a stand-alone hybrid renewable energy system, Energy. 141 (2017) 2288-2299. doi:10.1016/j.energy.2017.11.085.

[11] M. Castañeda, A. Cano, F. Jurado, H. Sánchez, L.M. Fernández, Sizing optimization, dynamic modeling and energy management strategies of a stand-alone PV/hydrogen/battery-based hybrid system, Int. J. Hydrog. Energy. 38 (2013) 38303845. doi:10.1016/j.ijhydene.2013.01.080.

[12] M. Bianchi, L. Branchini, C. Ferrari, F. Melino, Optimal sizing of grid-independent hybrid photovoltaic-battery power systems for household sector, Appl. Energy. 136 (2014) 805-816. doi:10.1016/j.apenergy.2014.07.058.

[13] S.B. Jeyaprabha, A.I. Selvakumar, Optimal sizing of photovoltaic/battery/diesel based hybrid system and optimal tilting of solar array using the artificial intelligence for remote houses in India, Energy Build. 96 (2015) 40-52. doi:10.1016/j.enbuild.2015.03.012.

[14] A. Gomes, C. Henggeler Antunes, A. Gomes Martins, "A multiple objective evolutionary approach for the design and selection of load control strategies" (IEEE Transactions on Power Systems (2004) (1173-1180)), IEEE Trans. Power Syst. 19 (2004) 2124. doi:10.1109/TPWRS.2004.838032.

[15] C. Drury B., L.K. Lawrie, Rethinking the TMY: is the "typical" meteorological tear best for building performance simulation?, Bentley Syst. 14th Conf. Int. Build. Perform. Simul. Assoc. (2015). 
[16] L. Danza, L. Belussi, I. Meroni, F. Salamone, F. Floreani, A. Piccinini, A. Dabusti, A Simplified Thermal Model to Control the Energy Fluxes and to Improve the Performance of Buildings, ATI 2016 - 71st Conf. Ital. Therm. Mach. Eng. Assoc. 101 (2016) 97-104. doi:10.1016/j.egypro.2016.11.013.

[17] J.P. Trovão, M.A. Silva, C.H. Antunes, M.R. Dubois, Stability enhancement of the motor drive DC input voltage of an electric vehicle using on-board hybrid energy storage systems, Appl. Energy. 205 (2017) 244-259. doi:10.1016/j.apenergy.2017.07.084.

[18] D. Ipsakis, S. Voutetakis, P. Seferlis, F. Stergiopoulos, C. Elmasides, Power management strategies for a stand-alone power system using renewable energy sources and hydrogen storage, Int. J. Hydrog. Energy. 34 (2009) 7081-7095. doi:10.1016/j.ijhydene.2008.06.051.

[19] G. Merei, C. Berger, D.U. Sauer, Optimization of an off-grid hybrid PV-Wind-Diesel system with different battery technologies using genetic algorithm, Sol. Energy. 97 (2013) 460-473. doi:10.1016/j.solener.2013.08.016.

[20] G. Ramos Ruiz, C. Fernández Bandera, T. Gómez-Acebo Temes, A. Sánchez-Ostiz Gutierrez, Genetic algorithm for building envelope calibration, Appl. Energy. 168 (2016) 691-705. doi:10.1016/j.apenergy.2016.01.075.

[21] E. Elbeltagi, T. Hegazy, D. Grierson, Comparison among five evolutionary-based optimization algorithms, Adv. Eng. Inform. 19 (2005) 43-53. doi:10.1016/j.aei.2005.01.004.

[22] R. Wu, G. Mavromatidis, K. Orehounig, J. Carmeliet, Multiobjective optimisation of energy systems and building envelope retrofit in a residential community, Appl. Energy. 190 (2017) 634-649. doi:10.1016/j.apenergy.2016.12.161.

[23] M.A. Lozano, J.C. Ramos, L.M. Serra, Cost optimization of the design of CHCP (combined heat, cooling and power) systems under legal constraints, Energy. 35 (2010) 794-805. doi:10.1016/j.energy.2009.08.022.

[24] D. Abbes, A. Martinez, G. Champenois, Eco-design optimisation of an autonomous hybrid wind-photovoltaic system with battery storage, IET Renew. Power Gener. 6 (2012) 358-371. doi:10.1049/iet-rpg.2011.0204.

[25] T. Khatib, A. Mohamed, K. Sopian, Optimization of a PV/wind micro-grid for rural housing electrification using a hybrid iterative/genetic algorithm: Case study of Kuala Terengganu, Malaysia, Energy Build. 47 (2012) 321-331. doi:10.1016/j.enbuild.2011.12.006.

[26] J. A. Duffie, W. A. Beckman, Solar Engineering of Thermal Processes, Fourth Edition, John Wiley \& Sons, 2013.

[27] EnergyPlus, Weather Data Sources, (n.d.). https://energyplus.net/weather/sources\#IWEC (accessed November 15, 2017).

[28] R. Buffat, S. Grassi, M. Raubal, A scalable method for estimating rooftop solar irradiation potential over large regions, Appl. Energy. 216 (2018) 389-401. doi:10.1016/j.apenergy.2018.02.008.

[29] ENF Solar, Annuaire Panneaux Solaires, (n.d.). https://fr.enfsolar.com/pv/panel/2 (accessed July 24, 2018).

[30] J.A. Crabb, N. Murdoch, J.M. Penman, SIMPLIFIED THERMAL RESPONSE MODEL., Build. Serv. Eng. Res. Technol. 8 (1987) 13-19.

[31] M. Orosz, Q. Altes-Buch, A. Mueller, V. Lemort, Experimental validation of an electrical and thermal energy demand model for rapid assessment of rural health centers in sub-Saharan Africa, Appl. Energy. 218 (2018) 382-390. doi:10.1016/j.apenergy.2018.03.004. 
[32] G. Capizzi, G.L. Sciuto, G. Cammarata, M. Cammarata, Thermal transients simulations of a building by a dynamic model based on thermal-electrical analogy: Evaluation and implementation issue, Appl. Energy. 199 (2017) 323-334. doi:10.1016/j.apenergy.2017.05.052.

[33] G. Fraisse, C. Viardot, O. Lafabrie, G. Achard, Development of a simplified and accurate building model based on electrical analogy, Energy Build. 34 (2002) 10171031. doi:10.1016/S0378-7788(02)00019-1.

[34] O. Schmidt, A. Gambhir, I. Staffell, A. Hawkes, J. Nelson, S. Few, Future cost and performance of water electrolysis: An expert elicitation study, Int. J. Hydrog. Energy. 42 (2017) 30470-30492. doi:10.1016/j.ijhydene.2017.10.045.

[35] A. Ganguly, D. Misra, S. Ghosh, Modeling and analysis of solar photovoltaicelectrolyzer-fuel cell hybrid power system integrated with a floriculture greenhouse, Energy Build. 42 (2010) 2036-2043. doi:10.1016/j.enbuild.2010.06.012.

[36] T. Zhou, B. Francois, Modeling and control design of hydrogen production process for an active hydrogen/wind hybrid power system, Int. J. Hydrog. Energy. 34 (2009) 21-30. doi:10.1016/j.ijhydene.2008.10.030.

[37] Mahytec, Solutions de stockage de l'hydrogène, (n.d.). http://www.mahytec.com/fr/nossolutions/ (accessed June 14, 2018).

[38] A. Bouscayrol, C.C. Chan, P. Barrade, J.P. Trovão, Energetic Macroscopic Representation, in: Hanoï, Vietnam, 2018.

[39] A. Bouscayrol, J.-P. Hautier, B. Lemaire-Semail, Graphic Formalisms for the Control of Multi-Physical Energetic Systems: COG and EMR, in: Syst. Des. Methodol. Electr. Energy Syst. Anal. Synth. Manag., 2013: pp. 89-124. doi:10.1002/9781118569863.ch3.

[40] S. Satyapal, J. Petrovic, C. Read, G. Thomas, G. Ordaz, The U.S. Department of Energy's National Hydrogen Storage Project: Progress towards meeting hydrogenpowered vehicle requirements, Catal. Today. 120 (2007) 246-256. doi:10.1016/j.cattod.2006.09.022.

[41] SBC Energy Institute, Hydrogen-Based Energy Conversion, 2014. http://www.4iscnmi.com/presentations/SBC-Energy-Institute_Hydrogen-based-energyconversion_FactBook-vf.pdf (accessed September 25, 2018).

[42] I. Staffell, R. Green, The cost of domestic fuel cell micro-CHP systems, Int. J. Hydrog. Energy. 38 (2013) 1088-1102. doi:10.1016/j.ijhydene.2012.10.090.

[43] ENEDIS, Consommation électrique par secteur d'activité, (n.d.). http://www.enedis.fr/consommation-electrique-par-secteur-dactivite (accessed June 16, 2018).

[44] M.J. Brandemuehl, W.A. Beckman, Transmission of diffuse radiation through CPC and flat plate collector glazings, Sol. Energy. 24 (1980) 511-513. doi:10.1016/0038092X(80)90320-5. 